\title{
Aptamer targeting EGFRvIII mutant hampers its constitutive autophosphorylation and affects migration, invasion and proliferation of glioblastoma cells
}

\author{
Simona Camorani ${ }^{1}$, Elvira Crescenzi ${ }^{1}$, David Colecchia ${ }^{2}$, Andrea Carpentieri ${ }^{3}$, \\ Angela Amoresano ${ }^{3}$, Monica Fedele ${ }^{1}$, Mario Chiariello² and Laura Cerchia ${ }^{1}$ \\ ${ }^{1}$ Istituto per I'Endocrinologia e I'Oncologia Sperimentale "G. Salvatore" (IEOS), Consiglio Nazionale delle Ricerche (CNR), \\ Naples, Italy \\ ${ }^{2}$ Istituto Toscano Tumori (ITT), Core Research Laboratory (CRL) and Consiglio Nazionale delle Ricerche (CNR), Istituto di \\ Fisiologia Clinica (IFC), Siena, Italy \\ ${ }^{3}$ Dipartimento di Scienze Chimiche, Università degli Studi di Napoli "Federico II", Naples, Italy \\ Correspondence to: Laura Cerchia, email: cerchia@unina.it \\ Keywords: aptamer, EGFRvIll, glioblastoma, PDGFRß, combined treatment
}

Received: July 16, 2015

Accepted: September 23, 2015

Published: October 10, 2015

This is an open-access article distributed under the terms of the Creative Commons Attribution License, which permits unrestricted use, distribution, and reproduction in any medium, provided the original author and source are credited.

\section{ABSTRACT}

Glioblastoma Multiforme (GBM) is the most common and aggressive human brain tumor, associated with very poor survival despite surgery, radiotherapy and chemotherapy.

The epidermal growth factor receptor (EGFR) and the platelet-derived growth factor receptor $\beta$ (PDGFRß) are hallmarks in GBM with driving roles in tumor progression. In approximately half of the tumors with amplified EGFR, the EGFRvIII truncated extracellular mutant is detected. EGFRvIII does not bind ligands, is highly oncogenic and its expression confers resistance to EGFR tyrosine kinase inhibitors (TKIs). It has been demonstrated that EGFRvIII-dependent cancers may escape targeted therapy by developing dependence on PDGFR $\beta$ signaling, thus providing a strong rationale for combination therapy aimed at blocking both EGFRvIII and PDGFRß signaling.

We have recently generated two nuclease resistant RNA aptamers, CL4 and Gint4.T, as high affinity ligands and inhibitors of the human wild-type EGFR (EGFRwt) and PDGFRß, respectively.

Herein, by different approaches, we demonstrate that CL4 aptamer binds to the EGFRvIII mutant even though it lacks most of the extracellular domain. As a consequence of binding, the aptamer inhibits EGFRvIII autophosphorylation and downstream signaling pathways, thus affecting migration, invasion and proliferation of EGFRvIII-expressing GBM cell lines.

Further, we show that targeting EGFRvIII by CL4, as well as by EGFR-TKIs, erlotinib and gefitinib, causes upregulation of PDGFR $\beta$. Importantly, CL4 and gefitinib cooperate with the anti-PDGFR $\beta$ Gint4.T aptamer in inhibiting cell proliferation.

The proposed aptamer-based strategy could have impact on targeted molecular cancer therapies and may result in progresses against GBMs.

\section{INTRODUCTION}

Glioblastoma multiforme (GBM) is a malignant and lethal form of brain cancer. The current standard for treatment of GBM consists of maximal surgical resection followed by radiotherapy with concomitant temozolomide, which frequently produces adverse effects, limiting therapeutic dosage increase. Despite treatment, the median 
survival for GBM patients remains less than 1.5 years [1]. Therefore, there is a pressing need to identify novel methods to more efficiently treat these tumors.

Epidermal growth factor receptor (EGFR) is a potent driver of GBM. EGFR gene amplification and overexpression occur in about $50 \%$ of primary GBMs and approximately half of tumors with amplification of the wild-type EGFR (EGFRwt) expresses the oncogenic mutant EGFR variant III (EGFRvIII, EGFR type III, de2-7 or $\triangle E G F R$ ) [2,3]. The overexpression of EGFRvIII with EGFR amplification is suggested as the strongest predictor of poor survival in GBMs [4-6]. EGFRvIII is generated by an in-frame deletion of $801 \mathrm{bp}$ of coding sequence from exons 2 to 7 that removes amino acids 6 to 273 in the extracellular region of the EGFRwt. Thus, compared to EGFRwt, the truncated EGFRvIII cannot bind any known EGFR ligands but constitutively signals to downstream effector molecules [7].

EGFRvIII greatly enhances GBM tumorigenicity in vivo $[8,9]$ and stimulates cell invasion in vitro and in vivo $[10,11]$. Different mechanisms of cooperation between EGFRwt and EGFRvIII have been reported, promoting malignant progression [12-15] and suggesting combinatorial targeting of both EGFR species. Regrettably, the results have so far been unsatisfactory in clinic given the high resistance of GBM to firstgeneration EGFR inhibitors, including erlotinib and gefitinib tyrosine kinase inhibitors (TKIs) and, to date, there is little evidence to sustain the use of such inhibitors as monotherapy [16-18]. One emerging cause that dictates GBM escape from EGFR-targeted therapies is the occurrence of alternative kinase signaling pathways that compensate the pharmacological perturbations. It has been recently shown that inhibition of EGFRvIII in GBM leads to increase of platelet-derived growth factor receptor $\beta$ (PDGFR $\beta$ ) expression and signaling as a growth rescue mechanism $[19,20]$, providing the rationale for coinhibition of these receptors.

We generated a nuclease resistant 2'F-Pyrimidines (2'F-Py)-containing RNA aptamer, named CL4, as a high affinity (Kd: $10 \mathrm{nmol} / \mathrm{l})$ ligand of human EGFR [21]. The aptamer specifically binds to the extracellular domain of the wild-type receptor thus inhibiting ligand-dependent EGFR autophosphorylation and downstream signaling pathways [21, 22].

Herein, we demonstrate that CL4 aptamer binds to the EGFRvIII mutant despite the deletion. Importantly, it inhibits EGFRvIII activation and constitutive signaling, thus interfering with migration, invasion and growth of GBM cells. We show that targeting EGFRvIII by CL4 causes upregulation of PDGFR $\beta$ and that CL4 and gefitinib cooperate with a validated anti-PDGFR $\beta$ aptamer [22] in inhibiting EGFRvIII-positive GBM cells growth.

Our results strongly encourage further in vivo investigation for aptamer-based approaches aimed at developing new therapeutics for GBM and other cancer types that depend on EGFRvIII and PDGFR $\beta$ for survival and growth.

\section{RESULTS}

\section{CL4 binds to EGFRvIII mutant on cell surface}

CL4 aptamer is a 39-mer 2'F-Py RNA that binds at high affinity to the extracellular domain of human EGFRwt both if expressed on cancer cells and in a soluble, recombinant form [21, 22]. Being EGFRvIII mutant a very appealing target for GBM treatment, here we investigated whether CL4 binds to EGFRvIII, even though the mutant receptor lacks most of domains I and II in the extracellular part of the protein.

Mouse NIH3T3 fibroblast cells, which show little to no expression of endogenous EGFRwt [15, 23], were engineered to overexpress human EGFRvIII (NIH/ EGFRvIII) (supplementary Figure S1, left) and used as a testing platform for CL4 specificity. We first applied reverse transcription quantitative polymerase chain reaction (RT-qPCR) methods to detect cell binding of the aptamer. As shown (Figure 1A), CL4 bound, in a dose dependent manner, to NIH/EGFRvIII whereas it did not bind to cells transfected with empty vector $(\mathrm{NIH} /$ ctr). Results are expressed relatively to the background binding detected with a scrambled sequence (CL4Sc), used as a negative control. Next, we analyzed the binding of the fluorescent FAM-labelled CL4 to EGFRvIII on the surface of unpermeabilized cells, by confocal microscopy. As shown in Figure 1B and supplementary Figure S2A, CL4 aptamer localizes at membrane level of NIH/EGFRvIII, showing puncta of colocalization with EGFRvIII after only 5 minutes incubation whereas multiple CL4 dots were accumulated in the cytoplasmic side of cell membrane in 10 minutes incubation. Aptamer binding seems to be highly specific for NIH/EGFRvIII and very little to no signal for CL4 was revealed on NIH/ctr cells (supplementary Figure S2B). Furthermore, the uptake mechanism for anti-EGFR aptamer was investigated. To this aim NIH/EGFRvIII cells were incubated with CL4 aptamer for 15 and 30 minutes and then fixed, permeabilized and labelled with anti-EGFR and anti-EEA1 antibodies. As shown in Figure 1C and 1D, the aptamer colocalizes with EGFRvIII inside the cells. Further, active internalization of CL4 aptamer occurred by endosome recycling pathway [24] as demonstrated by the colocalization of CL4 EGFRvIII-bound with early endosome antigen 1 (EEA1), the main endosome marker (Figure 1C and supplementary Figure S3A). Only a very low CL4-signal was observed in $\mathrm{NIH} /$ ctr cells (supplementary Figure S3B).

As in vitro GBM models to detect CL4 binding to EGFRvIII, we used the highly tumorigenic U87MG cells 
A

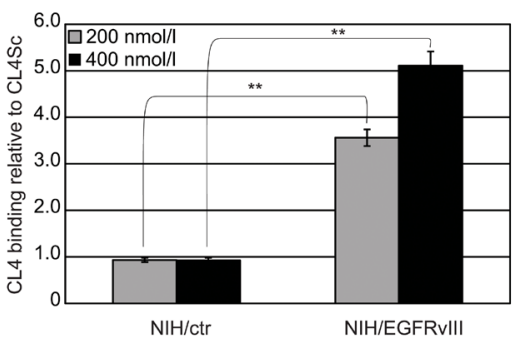

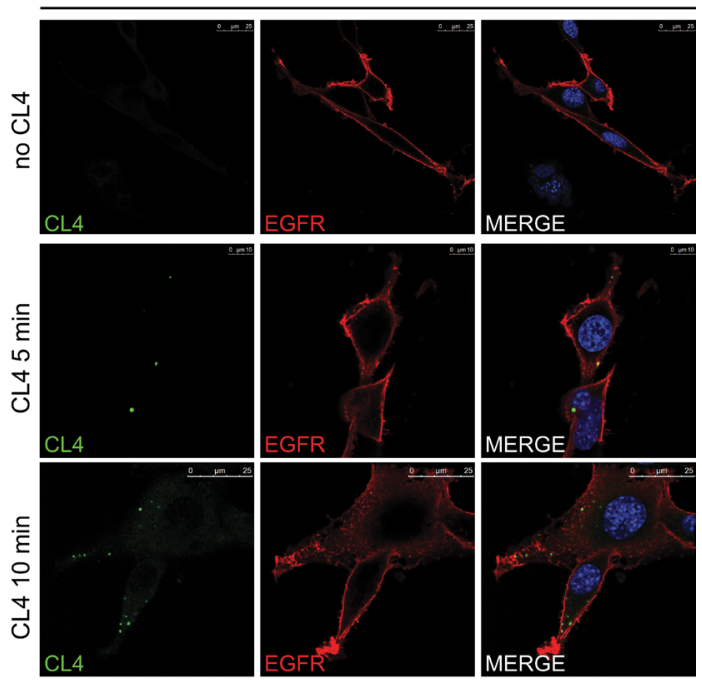

C

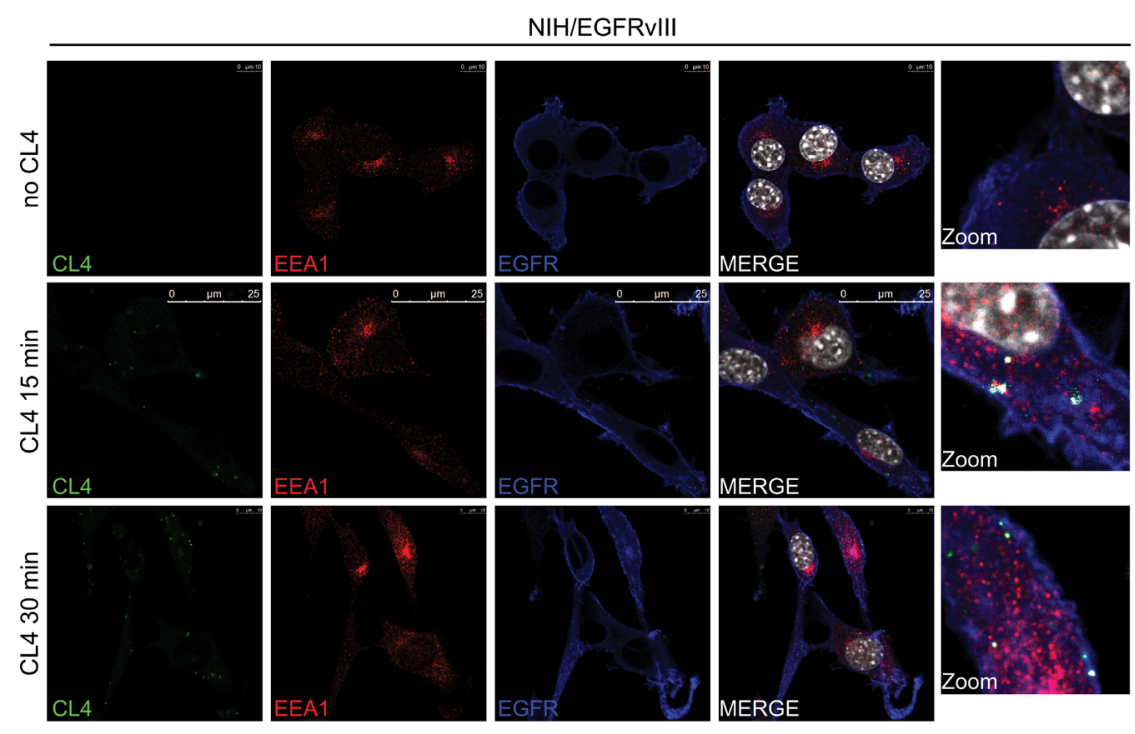

D

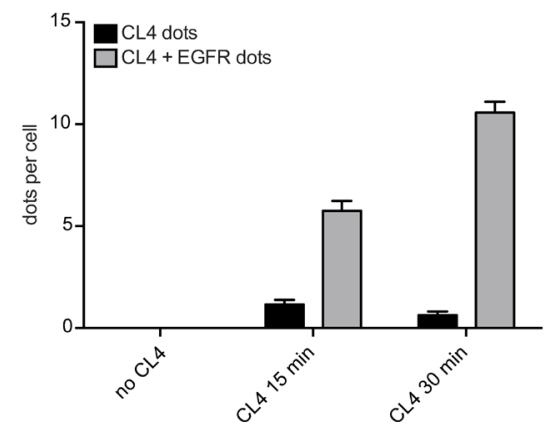

Figure 1: CL4 binds and internalizes into NIH/EGFRvIII cells. A. Binding of 200 and $400 \mathrm{nmol} / \mathrm{l}$ CL4 to the indicated cells was detected by RT-qPCR. Results are expressed relative to the background binding detected with CL4Sc used as a negative control. Bars depict means $\pm \mathrm{SD}(n=3)$. ${ }^{* *} P<0.01$. B. NIH/EGFRvIII cells were incubated with $2.5 \mu \mathrm{mol} / 1$ FAM-labelled CL4 for 5 and 10 minutes. Cells were fixed and labelled with anti-EGFR antibody without permeabilization. CL4, EGFRvIII and nuclei are visualized in green, red and blue, respectively. C. and D. NIH/EGFRvIII cells were incubated with $2.5 \mu \mathrm{mol} / \mathrm{l}$ FAM-labelled CL4 for 15 and 30 minutes. Cells were fixed, permeabilized and labelled with anti-EGFR and anti-EEA1 antibodies. In C., CL4, EEA1, EGFRvIII and nuclei are visualized in green, red, blue and grey, respectively. D. Total CL4 dots per cell were counted in each frame of Z-stacks, then EGFRvIII signal was evaluated for each CL4 dot (signal lower than 20\% was considered negative for colocalization while higher than 20\% was considered positive). 
and a primary GBM cell line, both stably engineered to express EGFRvIII (U87MG/EGFRvIII and VS-GB/ EGFRvIII, respectively) since cultures established from tumors when grown in vitro lose EGFRvIII expression, as reviewed in [17]. Differently from U87MG cells, the VS-GB cell line does not express endogenously EGFRwt mRNA (supplementary Figure S1, right) and protein (supplementary Figure S1, left) at detectable levels. Accordingly to the above findings, CL4 bound to U87MG/ EGFRvIII, as assessed by both RT-qPCR (Figure 2A) and flow cytometry (Figure 2B), at a higher extent with respect to parental U87MG cells. Further, it recognized VS-GB/ EGFRvIII cells but not control cells (Figure 2C), thus confirming its specificity for EGFRvIII also in the absence of EGFRwt.

Thus, in an attempt to identify key amino acids of the receptor engaged in direct interactions with the aptamer, photo-chemical cross-linking was induced between the EGFRwt protein and the CL4 and then analyzed by a mass spectrometry (MS)-based approach. Briefly, the aptamer was combined in a 1:1 molar ratio with the extracellular domain of human EGFRwt in a soluble form and irradiated with UV light at $254 \mathrm{~nm}$. The cross-linked products were digested with trypsin and the peptide mixture was then submitted to enzymatic hydrolysis with $\mathrm{T} 1$ ribonuclease to digest the polynucleotide chain. The resulting mixture was directly analyzed by matrix-assisted laser-desorption ionization (MALDI)-MS to identify the amino acid residues involved in the linkage with the CL4 aptamer. Figure 2D shows the MALDI spectra obtained. Most of the signals were assigned to EGFR fragments on the basis of their molecular mass and the specificity of the enzyme. It is worth noting that MALDI spectrum in the absence of the aptamer showed the occurrence of $\mathrm{m} / \mathrm{z}$ 694.34, corresponding to peptide 495-500 (b). The same signal disappeared after cross-linking reaction (a) and two new signals occurred at $\mathrm{m} / \mathrm{z} 2240.96$ and 2582.02 that could not be assigned to any fragment within the protein sequence and were thus candidates for intermolecular cross-linked fragments (compare c and e to $\mathrm{d}$ and $\mathrm{f}$ ). On the basis of the EGFR sequence and ribonuclease T1 digestions products, the two signals were identified as peptide 495-500, lying in the domain IV, linked to AGGC and GAGGC nucleotides, respectively. These results are in good agreement with the CL4 ability to bind to the EGFRvIII mutant given that the domain IV of EGFRwt is still preserved in the EGFRvIII mutant despite the deletion event.

\section{CL4 interferes with constitutive EGFRvIII activation and downstream signaling}

As a next step, we asked whether CL4 interferes with the autophosphorylation activity of EGFRvIII in U87MG/EGFRvIII cells. To minimize EGFRwt basal (unstimulated) phosphorylation, cells were maintained in low $(2 \%)$ serum concentration for 6 hours before aptamer treatment. In these conditions, EGFRvIII was constitutively phosphorylated while basal activation/ tyrosine phosphorylation of EGFRwt was undetectable (Figure 3A). As shown in Figure 3B, CL4 treatment (200 nmol/l) of U87MG/EGFRvIII cells attenuated activation of EGFRvIII reaching about $50 \%$ inhibition of phosphorylation following 6 hours-incubation, where it did not affect the total level of the EGFRvIII protein. No further increase in the inhibitory effect was observed by increasing either the aptamer concentration or the incubation time (not shown). Total and phospho-EGFRvIII levels were unaffected by CL4Sc negative control.

It has been reported that EGFRvIII mutant forms constitutively active receptor homodimers $[25,26]$ that are stabilized by intermolecular-disulfide bonds through free cysteine residues resulting as a consequence of the deletion event [27, 28]. Moreover, forced dimerization of EGFRvIII by using genetic strategies enhances receptor phosphorylation and downstream signaling, leading to increased GBM cell proliferation [29]. Thus, we asked whether the observed CL4-dependent reduction of EGFRvIII phosphorylation might be due to the aptamer's ability to hamper the formation of phosphorylated disulfide-bonded EGFRvIII complexes. To this aim, extracts from U87MG/EGFRvIII cells treated with CL4 or CL4Sc were run on sodium dodecyl sulfate polyacrylamide gel electrophoresis (SDS-PAGE) under non-reducing or reducing condition and blotted with antiEGFR and anti-phospho-EGFR antibodies. As shown in Figure 3C (IB: EGFR, high exposure), a band compatible with the EGFRvIII dimer was clearly observed under nonreducing condition (left, arrowhead) which disappeared under reducing condition (right). The immunoblot with anti-phospho-EGFR antibodies revealed that this species was strongly phosphorylated. Remarkably, treating the cells with CL4 caused a drastic reduction of such phosphorylation. Under these conditions, no detectable disulfide-bonded EGFRwt homodimer was observed, as assessed by comparing the electrophoretic profile of lysates from U87MG/EGFRvIII and parental U87MG cells. Further, a substantial reduction of phosphorylation of EGFRvIII downstream effectors signal transducer and activator of transcription 3 (STAT3) and extracellular signal-regulated kinase (ERK) 1/2 was observed upon CL4 treatment of the cells (Figure 3D), suggesting a critical role of EGFRvIII dimerization for signaling. Conversely, no significant reduction was obtained on AKT activity, consistent with the lack of regulation of the phosphoinositide 3-kinase (PI3K) pathway in U87MG cells that harbor an inactivating mutation of the phosphatase and tensin homolog (PTEN) gene [30-32].

By using the same experimental conditions as for U87MG/EGFRvIII cells, we detected, also in NIH/ EGFRvIII cells, higher-order EGFRvIII complexes that were significantly reduced in the presence of CL4 ( 40\%, 
A

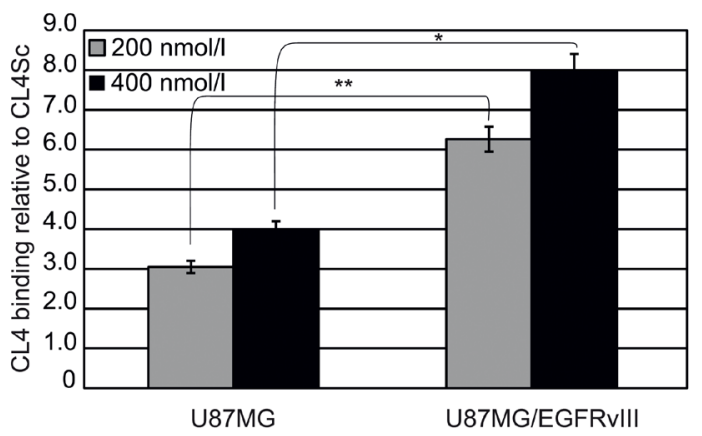

C

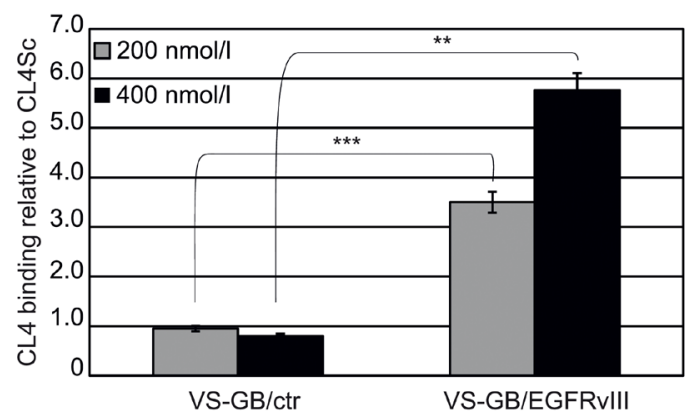

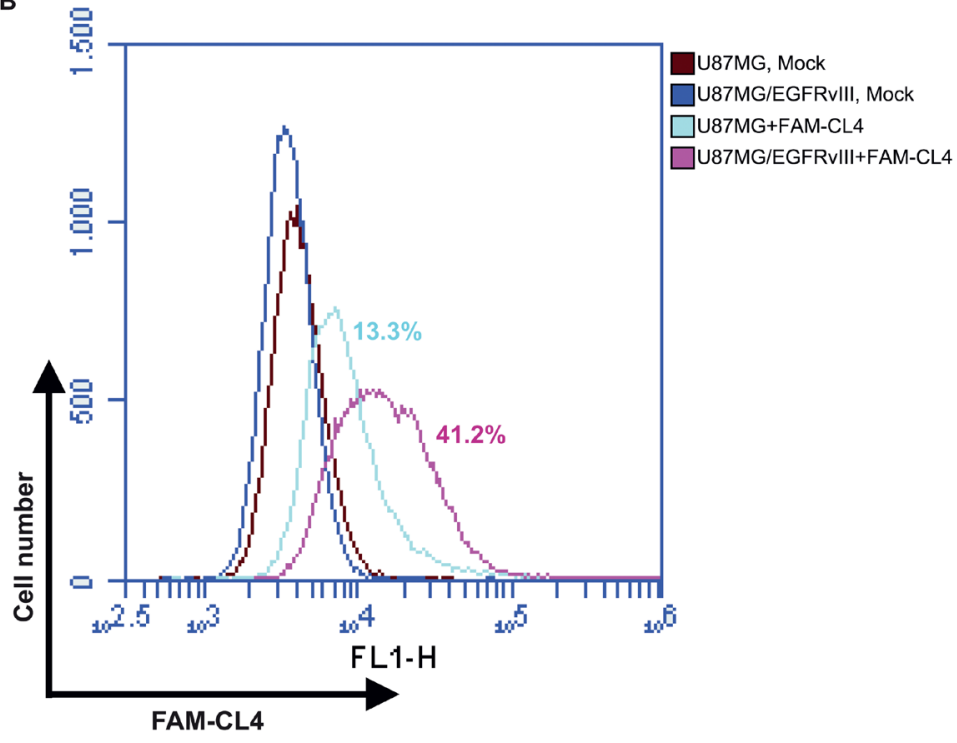

D
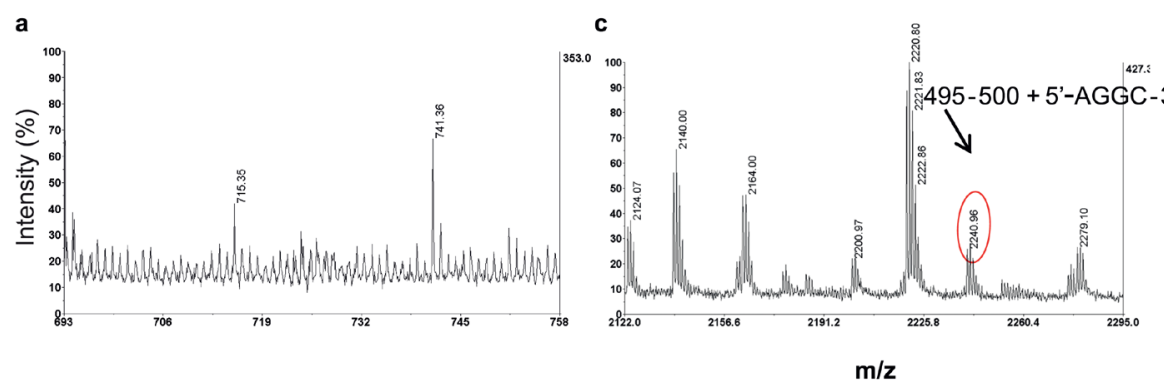

e $495-500+5^{\prime}-$ GAGGC-3'
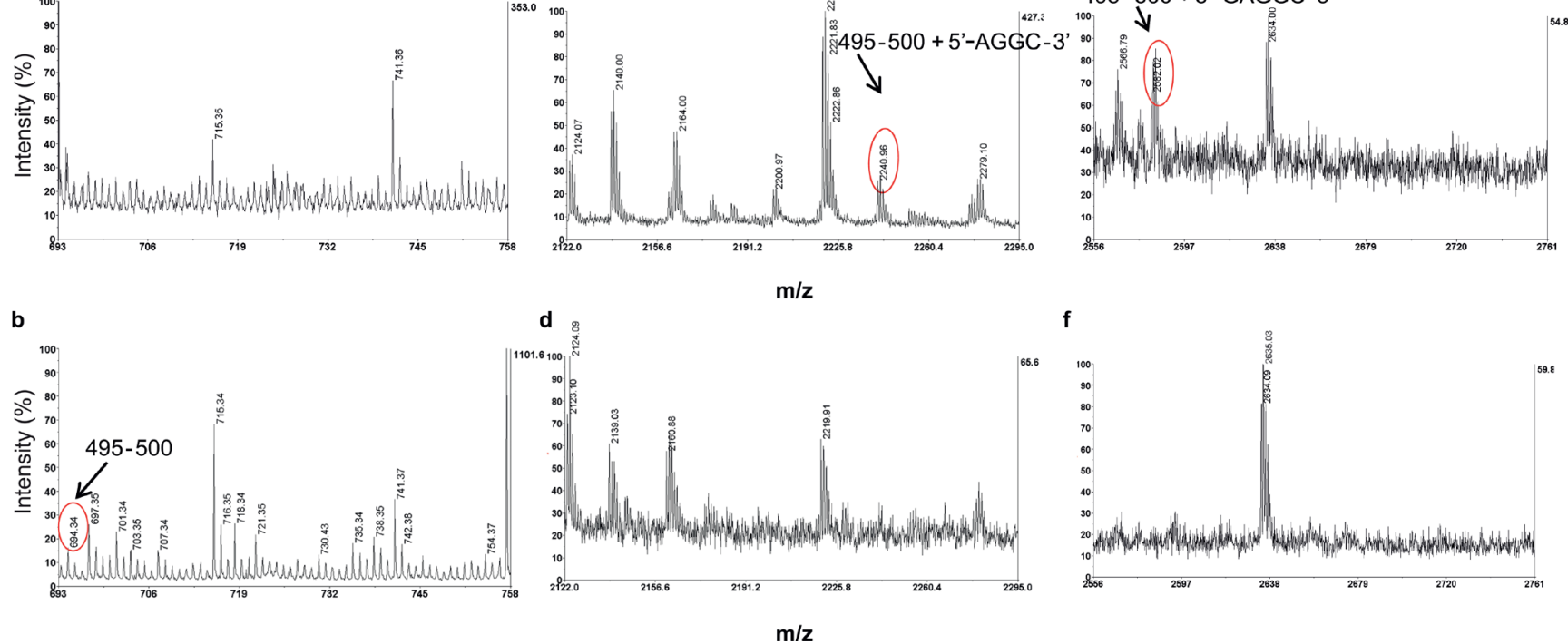

Figure 2: CL4 specifically interacts with EGFRvIII. Binding of CL4 to the indicated cell lines was detected by (A and C) RTqPCR or by B. flow cytometry. In $\mathbf{A}$ and $\mathbf{C}$, results are reported as in the legend to Figure 1A. Bars depict means \pm SD of three independent experiments. ${ }^{*} * P<0.001 ; * * P<0.01 ; * P<0.05$. In $\mathrm{B}$, the percentages of cells that are positive for FAM-labelled CL4 binding as compared to background levels, detected with mock-treated cells, are reported. D. Partial MALDI-MS spectra of the cross-linked product $(\mathrm{a}, \mathrm{c}, \mathrm{e})$ and of the control isolated protein $(\mathrm{b}, \mathrm{d}, \mathrm{f})$ digested with trypsin and $\mathrm{T} 1$ ribonuclease. The attribution of the cross-linked peptides is shown. 
A
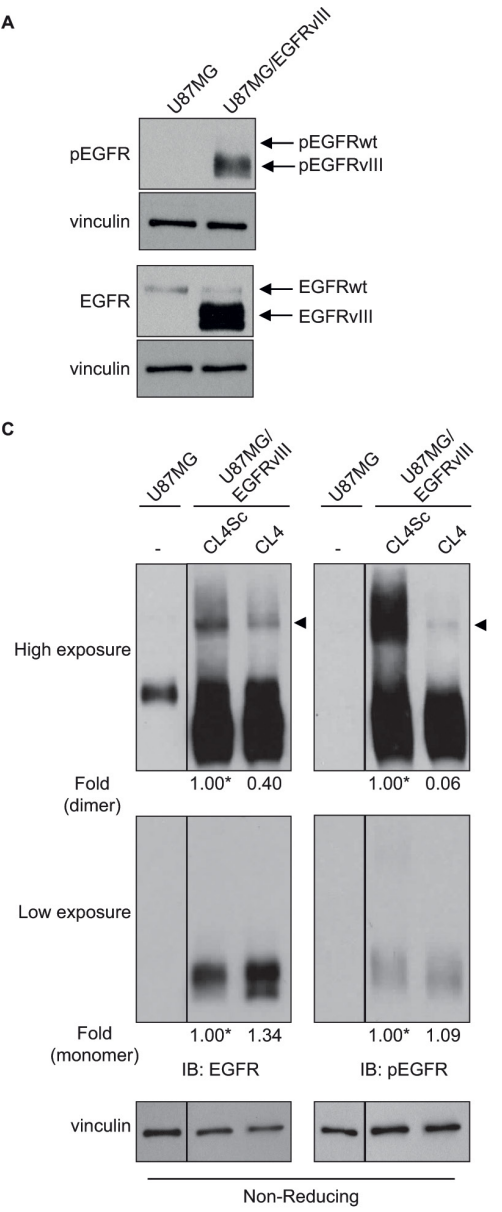

D

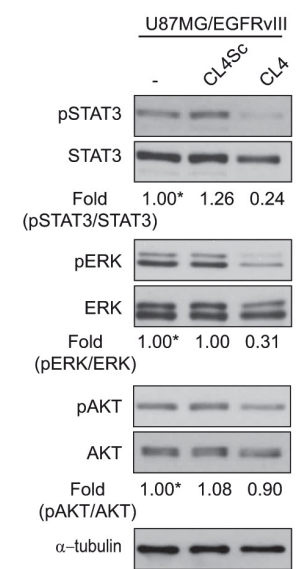

B

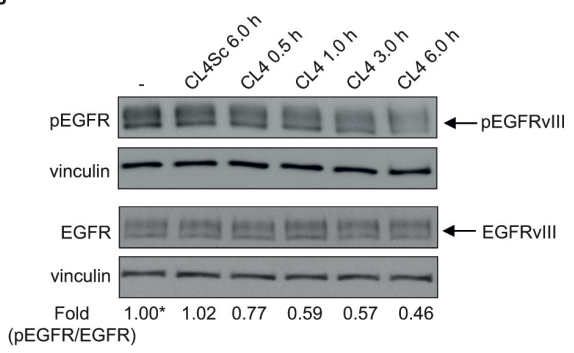

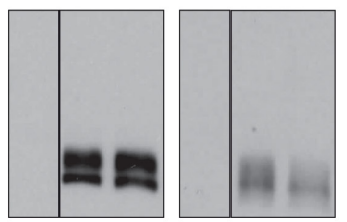

IB: EGFR IB: pEGFR

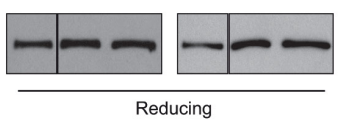

$\mathrm{E}$

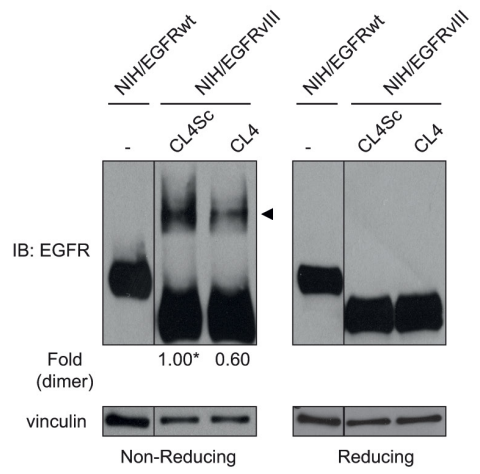

Figure 3: CL4 hampers EGFRvIII activation. Lysates from A. U87MG and U87MG/EGFRvIII cells maintained in 2\% FBScontaining medium for 6 hours or from B. U87MG/EGFRvIII cells maintained in 2\% FBS-containing medium for 6 hours and then left untreated for further 6 hours or treated with $200 \mathrm{nmol} / 1$ CL4 or CL4Sc for the indicated times, were immunoblotted with anti-pEGFR and anti-EGFR antibodies, as indicated. In B, values below the blot indicate the ratio of pEGFR to total EGFR signal levels, normalized to the respective vinculin signal level, and reported as relative to untreated cells, arbitrarily set to 1 (labeled with asterisk). C. Equal amounts of lysates from U87MG or U87MG/EGFRvIII cells, maintained in $2 \%$ FBS for 6 hours and then treated with 200 nmol/1 CL4 or CL4Sc for 24 hours, were run on $6 \%$ SDS-PAGE under non-reducing (left) and reducing (right) conditions and immunoblotted with anti-EGFR and anti-pEGFR antibodies. D. Lysates from U87MG/EGFRvIII cells treated as in "C" were immunoblotted with anti-pSTAT3, anti-pERK and anti-pAKT antibodies, as indicated. Filters were stripped and reprobed with anti-STAT3, anti-ERK and anti-AKT antibodies. E. Lysates from NIH/EGFRwt or NIH/EGFRvIII cells treated as in "C" were immunoblotted with anti-EGFR antibody under non-reducing (left) and reducing (right) conditions. In $\mathbf{C}$ and $\mathbf{E}$, the band compatible with dimeric EGFRvIII species is depicted by the arrowhead. Equal loading was confirmed by immunoblot with anti-vinculin $(\mathbf{A}-\mathbf{C}, \mathbf{E})$ or anti- $\alpha$-tubulin antibody D.. (C-E) Values below the blots indicate signal levels relative to each controls, arbitrarily set to 1 (labeled with asterisk). 
respect to CL4Sc negative control) (Figure 3E).

\section{CL4 inhibits EGFRvIII-expressing glioblastoma cell migration and invasion}

Expression of EGFRvIII increases GBM cell motility in vitro $[33,34]$ that is further enhanced in cells missing PTEN [35]. Thus, to evaluate the biological significance of the CL4-dependent EGFRvIII inhibition, we investigated whether the aptamer could affect migration and invasion of GBM cells overexpressing EGFRvIII. We addressed this question in U87MG/EGFRvIII and Gli36 GBM cells stably expressing human EGFRvIII (Gli36/ EGFRvIII) (supplementary Figure S4A, left). The latter cell line, differently from U87MG, expresses PTEN (supplementary Figure S4A, right) $[31,36]$. We assessed the phosphorylation of ERK1/2 and AKT proteins as readout for monitoring the effect of CL4 in Gli36/EGFRvIII and, as shown (supplementary Figure S4B), a significant reduction not only of ERK1/2 but also of AKT activation was observed followed aptamer treatment, thus consistent with the wild-type PTEN expression in this cell line.

First, by using a scratch-wound assay that measures cell motility, we observed that, at 24 hours after scratch, the wound was barely visible in the plates containing U87MG/EGFRvIII cells (Figure 4A, left) whereas Gli36/ EGFRvIII cells still had a wide gap that was markedly reduced at 96 hours and almost closed at 120 hours (Figure 4A, right). Thus, U87MG/EGFRvIII cells have a greater migratory activity than Gli36/EGFRvIII cells, in good agreement with previous finding that PTEN expression negatively affects glioma cell migration also in the presence of the constitutively active EGFRvIII mutant $[34,35]$. Importantly, CL4 treatment of both cell lines significantly delayed the wound closure compared to mock-treated cells or cells treated with CL4Sc (Figure 4A).

Further, migration was analyzed by a "transwell migration assay" that assesses the chemotactic capacity of cells. As compared to cells treated with CL4Sc, in the presence of CL4, migration was reduced by $30 \%$ in U87MG/EGFRvIII cells and 45\% in Gli36/EGFRvIII cells at 24 and 72 hours, respectively (Figure 4B). At these experimental time-points, the influence of CL4 aptamer on cell proliferation was absent (supplementary Figure S5), thus indicating that the CL4-mediated decrease in migration occurred independently of cell proliferation.

We then examined the effect of CL4 on the capacity of the cells to invade through a matrigel-coated membrane by a "transwell invasion assay", which has been reported to mimic the whole process of cell invasion of basement membranes [37]. Using this assay, we observed that the invasion rate of U87MG/EGFRvIII and Gli36/EGFRvIII cells in the presence of CL4 treatment was significantly decreased compared with CL4Sc-treated cells (Figure 4C).
Altogether, these results show the ability of CL4 aptamer to affect GBM cell migration and invasion, also confirming the crucial role of EGFRvIII-associated signaling events for promoting cell motility.

\section{CL4 inhibits EGFRvIII-expressing glioblastoma cell growth}

Next, we performed growth curves experiments to determine whether the long-term CL4 treatment alters the proliferation rate of EGFRvIII-expressing GBM cells. We found that the aptamer reduced the proliferation of U87MG/EGFRvIII and Gli36/EGFRvIII cells causing about 50\% inhibition at day 11 with respect to cells mock-treated or treated with CL4Sc, that proliferated at comparable rates (Figure 5A).

We determined whether the aptamer was also able to reduce viability of U87MG/EGFRvIII and Gli36/EGFRvIII cells, by comparing its effects to those of erlotinib and gefitinib. As assessed by 3-(4,5-dimethylthiazol-2-yl)-2,5diphenyltetrazolium bromide (MTT) assay, both cell lines were highly resistant to 72 hours-treatment with erlotinib and gefitinib and significant decrease in cell viability was observed only in Gli36/EGFRvIII cells treated with high concentration of gefitinib $(10 \mu \mathrm{mol} / \mathrm{l})$ (Figure 5B, left). As a positive control of inhibitory efficacy, we verified that the two compounds, even at the lowest doses, consistently reduced viability of non-small cell lung cancer (NSCLC) HCC827 cells that are reported to be sensitive to EGFR TKIs [38] (supplementary Figure S6). Regarding the effect of CL4, we observed that the aptamer caused a time and dose-dependent inhibition of U87MG/EGFRvIII cell viability (Figure 5B, middle). Further, almost 30\% inhibition of Gli36/EGFRvIII cells viability was obtained in the presence of 72 hours-treatment with $200 \mathrm{nmol} / \mathrm{l} \mathrm{CL} 4$ aptamer, that is comparable with that obtained with the highest gefitinib concentration tested (10 $\mu \mathrm{mol} / \mathrm{l})$ (Figure 5B, right).

\section{CL4 cooperates with an anti-PDGFR $\beta$ aptamer to inhibit proliferation of EGFRvIII-expressing GBM cells}

Recently, a transcriptional repressive mechanism has been described by which EGFRvIII regulates PDGFR $\beta$ expression, showing that GBMs may evade EGFR TKIs treatment by developing PDGFR $\beta$-dependence for survival [19]. Differently from Gli36, that do not express detectable levels of PDGFR $\beta$ (not shown), U87MG are PDGFR $\beta$-positive, and both protein (Figure 6A, left) and mRNA (Figure 6A, right) levels were markedly reduced upon stable EGFRvIII overexpression. Furthermore, in agreement with previous findings [19], inhibition of EGFRvIII signaling by 24 hours-treatment with 5 $\mu \mathrm{mol} / 1$ erlotinib or gefitinib resulted in upregulation of 
A
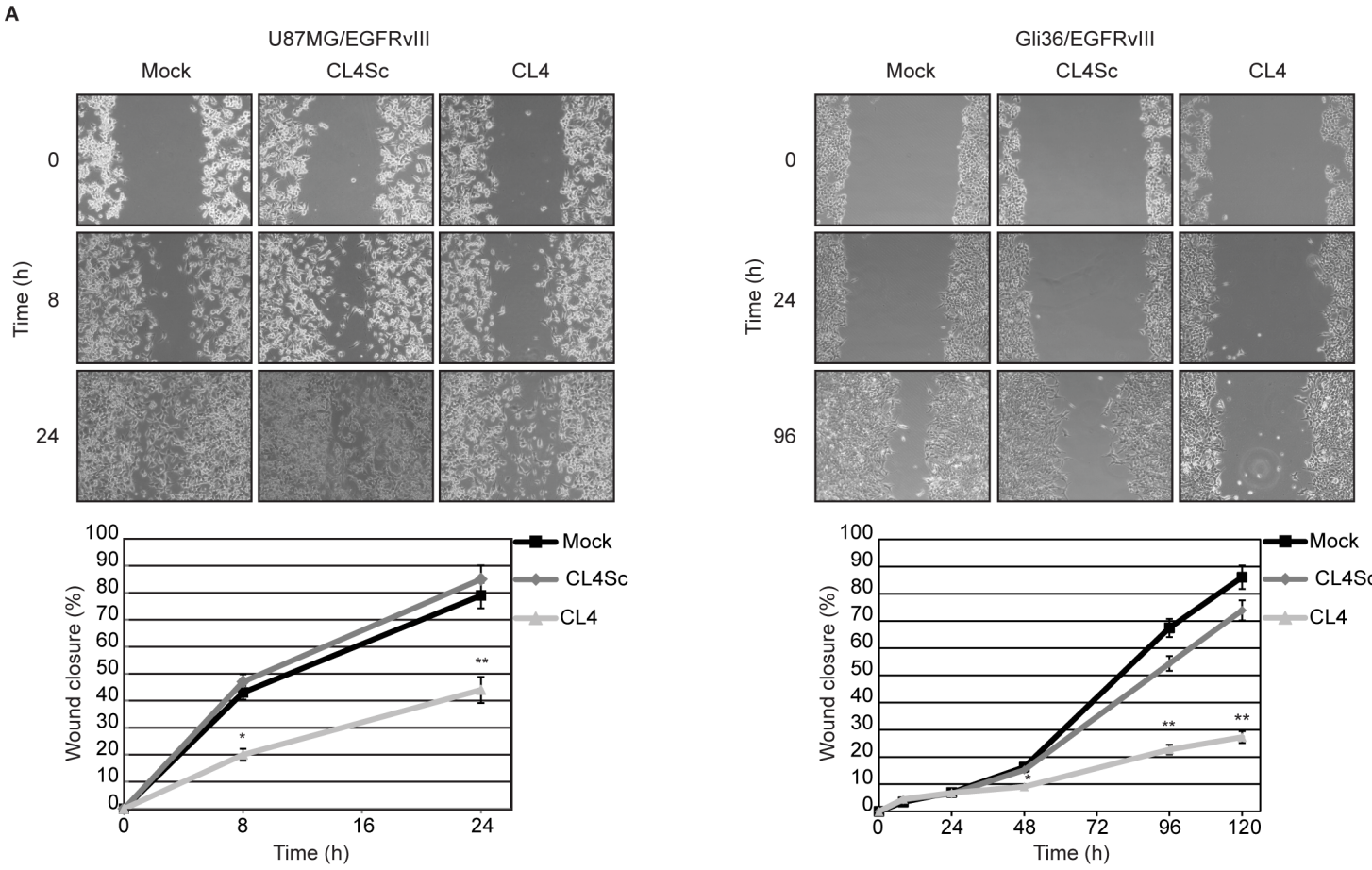

B
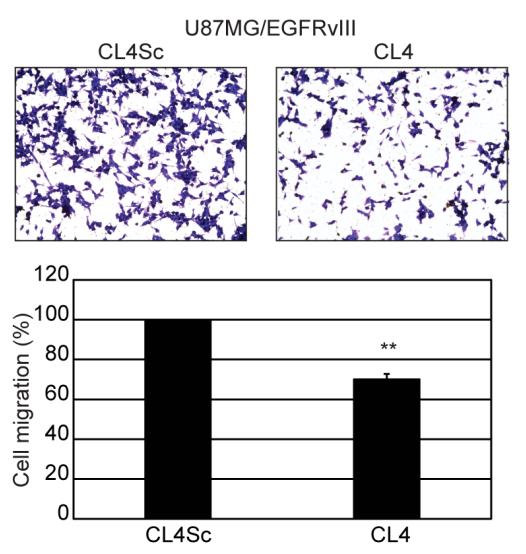

C

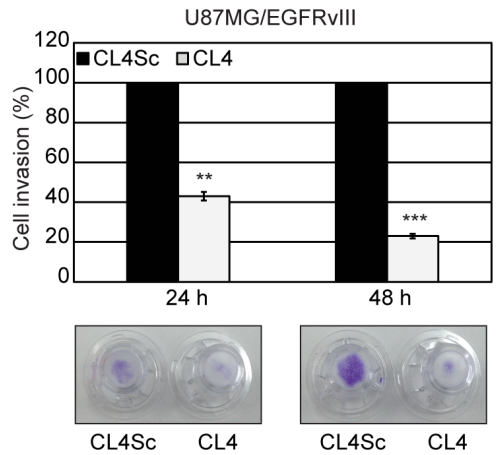

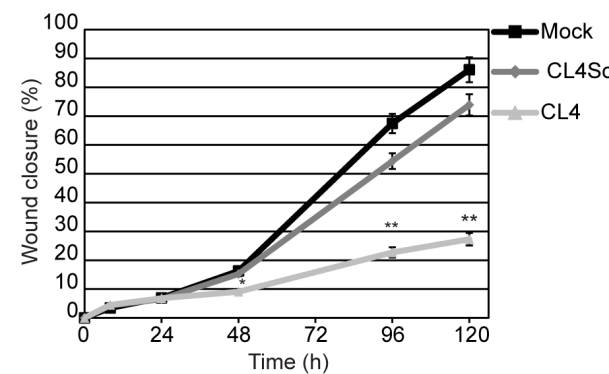

Gli36/EGFRvIII
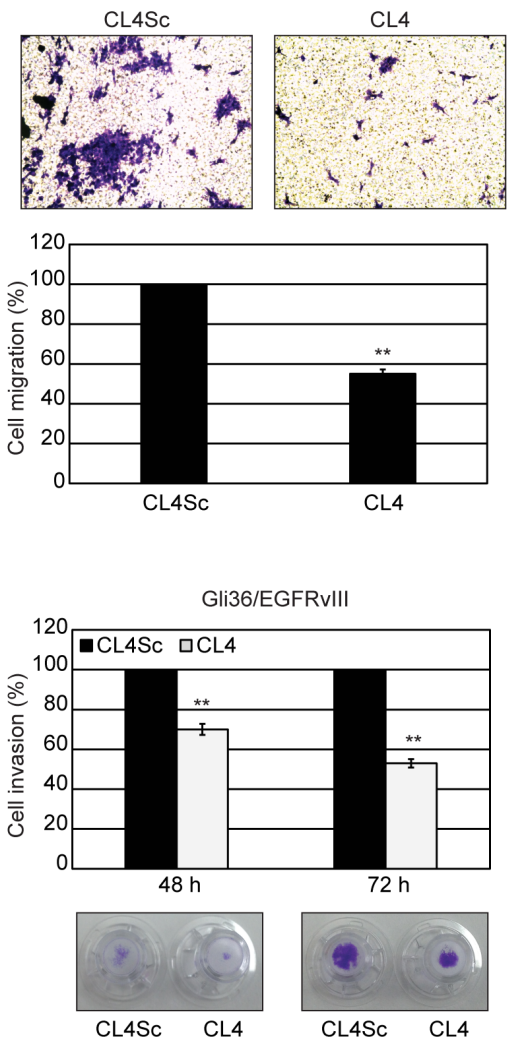

Figure 4: CL4 inhibits EGFRvIII-GBM cell migration and invasion. A. Subconfluent cell monolayers were subjected to scratch assays and mock-treated or treated with CL4 or CL4Sc up to 24 (U87MG/EGFRvIII) and 120 hours (Gli36/EGFRvIII). Phasecontrast microscopy images were taken at the indicated time and the extent of wound closure was calculated. B. Cell motility was analyzed by transwell migration assay in the presence of CL4 or CL4Sc for 24 (U87MG/EGFRvIII) and 72 hours (Gli36/EGFRvIII). C. Invasion U87MG/EGFRvIII and Gli36/EGFRvIII cells through matrigel toward 10\% FBS was carried out in the presence of CL4 or CL4Sc for the indicated times. $(\mathbf{B}, \mathbf{C})$ Data are presented as percentage of migrated or invaded cells in the presence of CL4 compared with CL4Sc control. Photographs of a representative experiment are shown. Each determination represents the average of three individual experiments and error bars represent SD. ${ }^{* * *} P<0.001 ; * * P<0.01 ; * P<0.05$ relative to CL4Sc. 
PDGFR $\beta$ (Figure 6B). Also, when U87MG/EGFRvIII cells were treated with CL4 aptamer, under the experimental conditions (24 hours treatment at $200 \mathrm{nmol} /$ 1-concentration) that caused phospho-EGFRvIII inhibition (see Figure 3C), we observed an induction of PDGFR $\beta$ protein and mRNA at a comparable extent with respect to EGFR TKIs (Figure 6C).

Thus, we tested whether targeting PDGFR $\beta$ by a highly specific aptamer (Gint4.T) [22] would enhance the sensitivity of U87MG/EGFRvIII cells to treatment with gefitinib or the CL4 aptamer. To this aim, cells were treated with a fixed dose of EGFR inhibitors $(200 \mathrm{nmol} / \mathrm{l}$ CL4 aptamer or $5 \mu \mathrm{mol} / 1$ gefitinib) for 24 hours, to cause upregulation of PDGFR $\beta$, and then treated for further 72 hours with CL4 or gefitinib, alone or in combination with $200 \mathrm{nmol} / 1$ anti-PDGFR $\beta$ Gint4.T aptamer. To test the effect of Gint4.T alone, cells were mock-treated for the first 24 hours and then treated with $200 \mathrm{nmol} / \mathrm{l}$ Gint4.T for the following 72 hours. As shown in Figure 7A, the

A

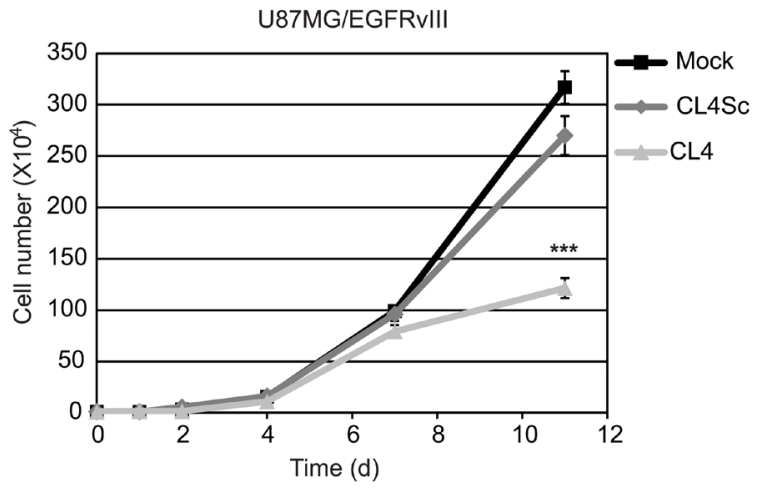

combined targeting of EGFRvIII/EGFR and PDGFR $\beta$ led to a higher decrease in cell viability compared to single receptor blocking. The most drastic effect was observed by using the two aptamers in combination, leading to almost $77 \%$ inhibition of cell viability compared to mock-treated cells or cells treated with CL4Sc (Figure 7A).

Further, in order to distinguish whether the above treatments caused cell death or reduction of cell proliferation, we performed staining with tetramethylrhodamine, ethyl ester (TMRE) and flow cytometry analysis, staining with trypan blue, morphological analysis or immunoblot analysis of PARP cleavage. No signs of apoptosis were observed following treatment of the cells with gefitinib or CL4, alone or in combination with Gint4.T aptamer (data not shown). Instead, a consistent reduction of cell proliferation was observed reaching about $50 \%$, in the presence of CL4 (or gefitinib) plus Gint4.T, compared to controls (Figure 7B).

Then, to test whether the combined blocking of

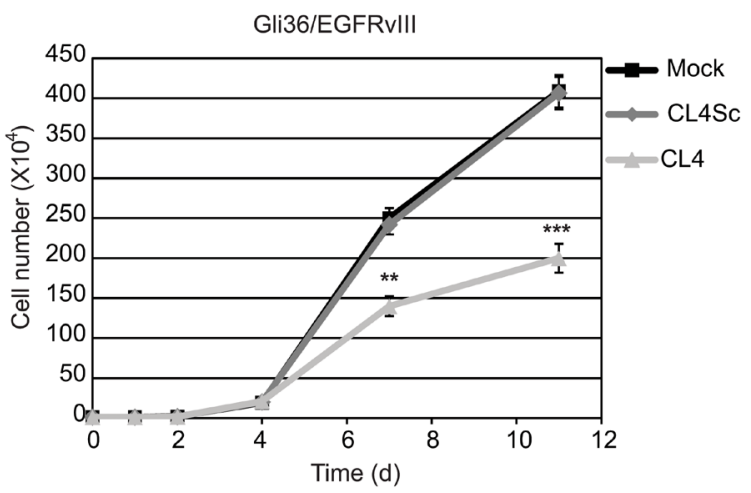

B
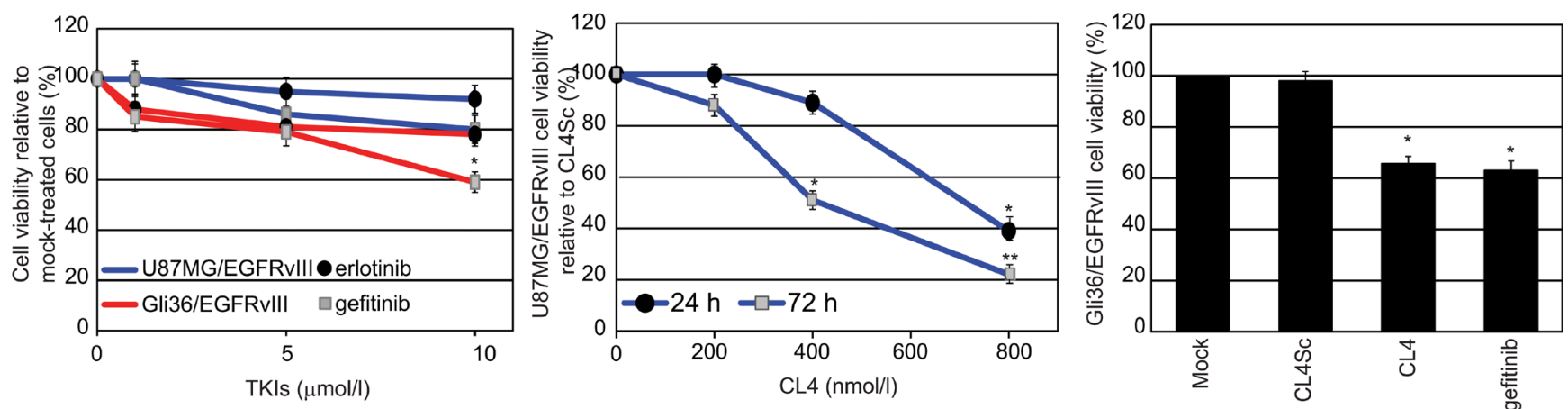

Figure 5: CL4 inhibits EGFRvIII-GBM cell growth. A. U87MG/EGFRvIII (left) and Gli36/EGFRvIII (right) cells (10 ${ }^{4}$ cells/3.5$\mathrm{cm}$ plate) were either mock-treated or treated with CL4 or CL4Sc (200 nmol/l-final concentration) and counted through the Bürker chamber at the indicated time points. The aptamer treatment was renewed each 24 hours. Growth curves represent the average of three independent experiments and error bars represent SD. $* * * P<0.001 ; * * P<0.01$ relative to CL4Sc. B. Left, U87MG/EGFRvIII (blue line) and Gli36/ EGFRvIII (red line) cells were mock-treated or treated for 72 hours with increasing amounts of erlotinib or gefitinb. Middle, U87MG/ EGFRvIII cells were treated for the indicated times with increasing amounts of CL4 or CL4Sc. Right, Gli36/EGFRvIII cells were mocktreated or treated for 72 hours with $10 \mu \mathrm{mol} / 1$ gefitinib or $200 \mathrm{nmol} / \mathrm{l} \mathrm{CL} 4$ or CL4Sc. Cell viability was analyzed and expressed as percent of viable treated cells with respect to mock-treated (left and right) or CL4Sc (middle) controls. In middle, no statistically significant variations among CL4Sc- and mock-treatment was obtained. Each determination represents the average of three individual experiments and error bars represent $\mathrm{SD} .{ }^{*} P P<0.01 ; * P<0.05$ relative to controls. 
EGFRvIII and PDGFR $\beta$ decreases cell proliferation also in the absence of EGFRwt expression, we used the primary GBM VS-GB/EGFRvIII cell lines. As shown, VSGB cells endogenously express PDGFR $\beta$, whose levels decrease in the presence of EGFRvIII overexpression (Figure 7C). Under the same treatment conditions as for U87MG/EGFRvIII cells, VS-GB/EGFRvIII cells viability was slightly decreased in the presence of CL4 aptamer as well as gefitinib. Importantly, a combination of CL4 (or gefitinib) and Gint4.T had a greater effect in inhibiting cell viability compared with either compound alone and the inhibition resulted stronger in the presence of the two aptamers (CL4 plus Gint4.T, 52\% inhibition; gefitinib plus Gint4.T, 43\% inhibition) (Figure 7D). Further, the cotreatment of the cells with the two aptamers reduced cell proliferation at a level similar to that observed in U87MG/

A
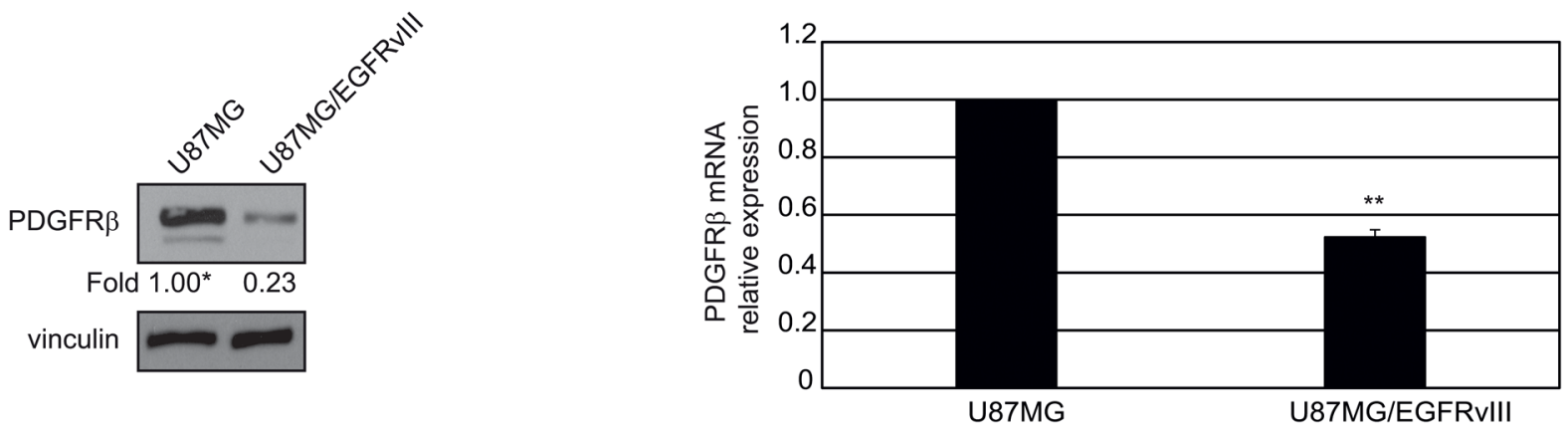

B
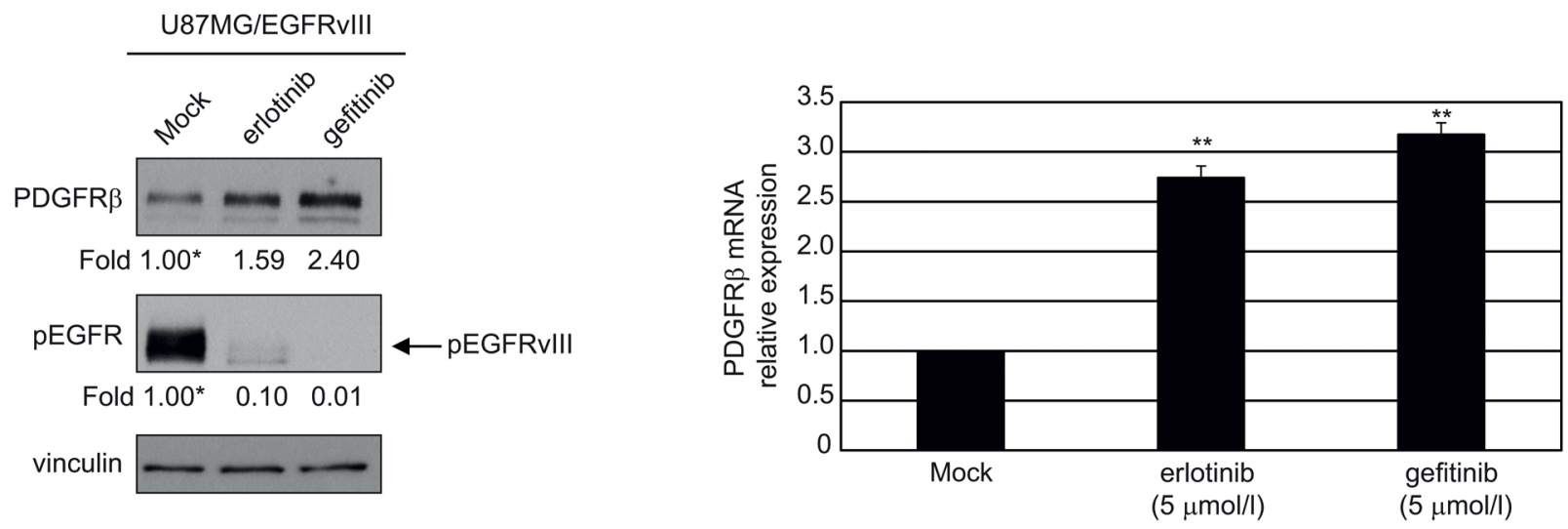

C
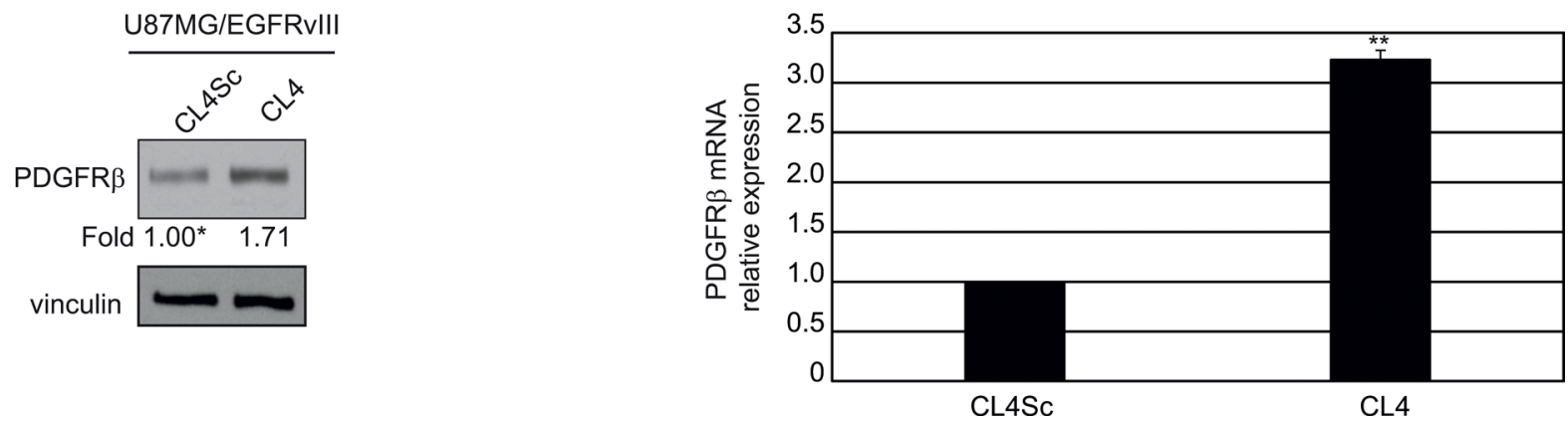

Figure 6: CL4-mediated inhibition of EGFRvIII induces upregulation of PDGFRß. The indicated cell lines were maintained in $2 \%$ FBS-containing medium for 24 hours in the absence A. and B. and in the presence of $5 \mu \mathrm{mol} / 1$ gefitinib or erlotinib B. or $200 \mathrm{nmol} / 1$ CL4 or CL4Sc C. . Cell lysates were analyzed by immunoblot with anti-PDGFR $\beta$ and anti-pEGFR antibodies, as indicated, and equal loading was confirmed by immunoblot with anti-vinculin antibody (left). Values below the blots indicate signal levels relative to each control, arbitrarily set to 1 (labeled with asterisk). PDGFR $\beta$ mRNA levels were analyzed by RT-qPCR (right). Bars depict means \pm SD of three independent experiments. ${ }^{* *} P<0.01$ relative to U87MG A., mock-treated B. or CL4Sc C. 
EGFRvIII cells (Figure 7E).

These results emphasize the use of the two aptamers aimed at targeting both EGFRvIII and PDGFR $\beta$ receptors.

\section{DISCUSSION}

Treatment of GBM has seen little improvement in the last 20 years despite targeted therapy and progress in surgery, radiation delivery and chemotherapy. Innovative therapeutic approaches are therefore needed to combat this highly lethal cancer. Therapies targeting EGFR, one of the most important oncoprotein involved in human cancer, while showing efficacy in other tumors, have not delivered long term benefits to GBM patients. EGFRvIII, the truncated extracellular mutant of the EGFR, is the most common EGFR mutant found in GBM and usually

A

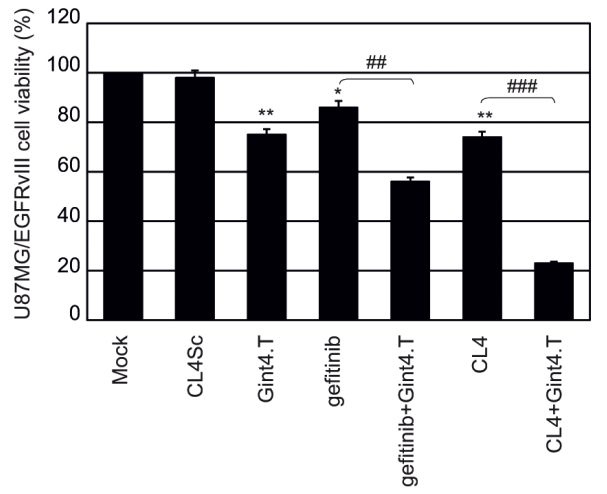

C

D

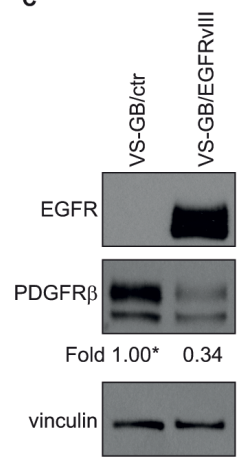

co-exists with EGFRwt. Increased EGFRvIII expression can play major roles in promoting tumor cell proliferation, migration, invasiveness and resistance to treatment [39, 40]. In this study, by using RT-qPCR, flow cytometry and immunofluorescence methods, we prove that the CL4 nuclease-stabilized RNA aptamer, previously generated as a neutralizing ligand for human EGFRwt [21, 22], is able to bind to EGFRvIII despite the lack of a portion of the extracellular region in EGFRvIII. Accordingly, crosslinking experiments among the soluble extracellular domain of EGFRwt and the aptamer revealed that the interaction between CL4 and EGFR is with domain IV of the receptor, which is still present in EGFRvIII. More detailed investigation of the interaction of CL4 to both variants, in a purified form, will help in defining whether the extracellular part of the protein, that is present in
B

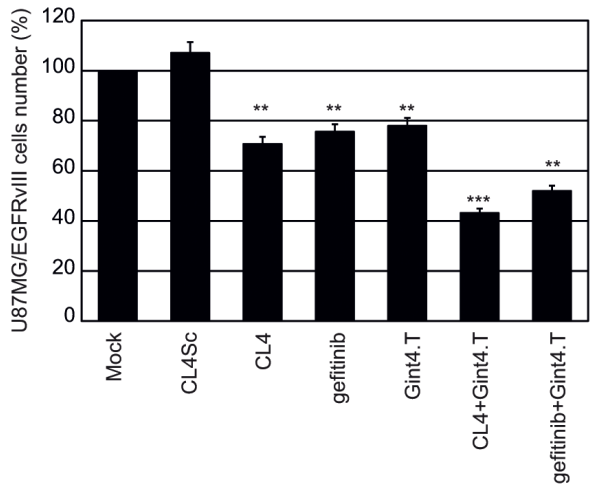

E
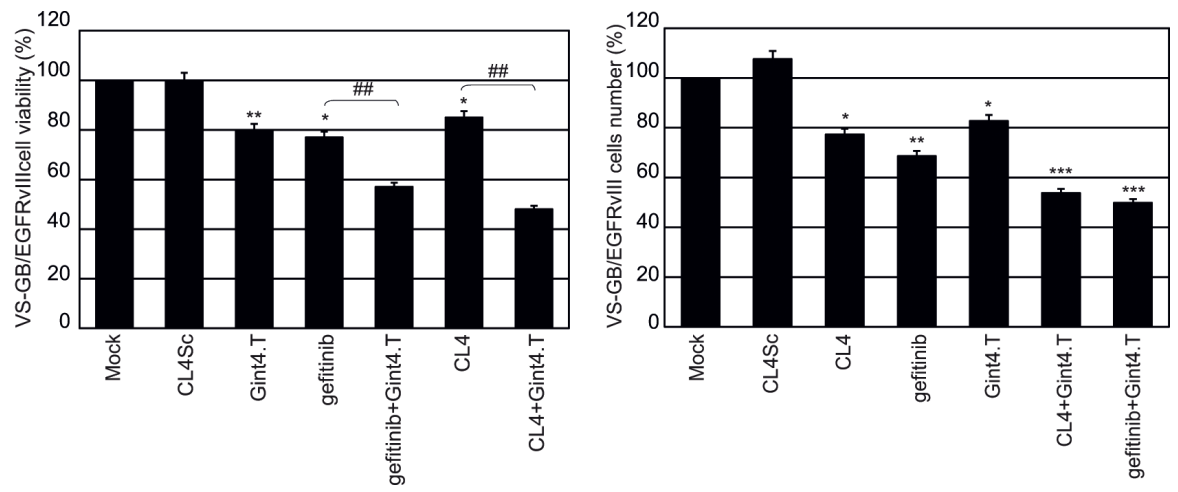

Figure 7: Combined inhibition of EGFRvIII and PDGFR $\beta$ in EGFRvIII-expressing GBM cells. A. and B. U87MG/ EGFRvIII cells (in A, $3.6 \times 10^{3}$ cells/well on 96-well plates; in B, $10^{5}$ cells/3.5-cm plate) were mock-treated or treated for 24 hours with $5 \mu \mathrm{mol} / 1$ gefitinib or $200 \mathrm{nmol} / 1 \mathrm{CL} 4$. Then the incubation was prolonged for further 72 hours with the above treatments alone or in combination with $200 \mathrm{nmol} / 1$ Gint4.T, by renewing the treatment each 24 hours. As a negative control, cells were treated with $400 \mathrm{nmol} / 1$ CL4Sc for 96 hours. In A, cell viability was analyzed and expressed as percent of viable treated cells with respect to mock-treated cells. In B, cells were counted through the Bürker chamber and cell number with respect to mock-treated cells, was reported. C. Lysates from VS-GB/ctr or VS-GB/EGFRvIII cells were immunoblotted with anti-EGFR and anti-PDGFR $\beta$ antibodies. Equal loading was confirmed by immunoblot with anti-vinculin antibody. Values below the blots indicate signal levels relative to VS-GB/ctr, arbitrarily set to 1 (labeled with asterisk). D. and E. VS-GB/EGFRvIII cells were treated as in A, B and cell viability D. and cell number E. were reported as for U87MG/ EGFRvIII cells. Bars depict means $\pm \mathrm{SD}$ of three independent experiments. ${ }^{*} P<0.01 ; * \mathrm{P}<0.05$ relative to controls (mock-treated and CL4Sc). \#\#\# $P<0.001$; \#\# $P<0.01$. 
EGFRwt but not in EGFRvIII, could have a role in modulating the binding affinity and specificity.

It has been clearly shown that EGFRvIII monomers can pair and form disulfide-bonded homodimers that enhance receptor oncogenicity [27, 28]. Further, chemically induced dimerization of a chimeric EGFRvIII in U87MG cells causes an increase of EGFRvIII and ERK1/2 phosphorylation levels, strengthens receptor tumorigenic signal and reduces survival of U87MG intracranial xenograft-bearing mice [29]. Moreover, it has been reported that gefitinib and other quinazoline TKIs, while inhibiting multiple EGFRvIII signaling pathways at high and repeated doses, when used at low concentrations, cause augmented homodimerization of the receptor, increased signaling to ERK1/2 and stimulation of proliferation and anchorage-independent growth of EGFRvIII-expressing GBM cells [41, 42]. In agreement with these observations, we show that the treatment of EGFRvIII-expressing U87MG cells with CL4 strongly inhibits the formation of high-order EGFRvIII active complexes that is accompanied by a consistent reduction of the phosphorylation of ERK1/2 and STAT3 downstream signaling effectors. Conversely, it does not affect AKT activity in U87MG/EGFRvIII cells. This is likely due to a lack of regulation in the PI3K pathway in these PTEN negative cells, since when applied to GBM PTEN-positive Gli36/EGFRvIII cells, the aptamer was able to reduce AKT phosphorylation.

Given the important contributing role of ERK1/2 and STAT3 pathways to the malignant phenotype of EGFRvIII-expressing GBM cells [15, 33, 42-44], we looked at the effects of CL4 on migration, invasion and proliferation of U87MG/EGFRvIII and Gli36/EGFRvIII cells. In agreement with previous reports indicating that the expression of EGFRvIII in GBM cells promotes cell migration, confers a significant growth advantage and enhance tumorigenic activity also in the context of EGFRwt expression [33, 45-47], we found that U87MG/ EGFRvIII cells had a higher proliferation rate and ability to migrate (in both "scratch" tests and "transwell" assays) compared to mock-transfected U87MG cells (data not shown). Importantly, when applied to U87MG/EGFRvIII and Gli36/EGFRvIII cells, CL4 aptamer significantly reduced cell migration, invasion and proliferation.

Recent reports indicate that targeting EGFRvIII causes the occurrence of parallel signaling pathways that render GBM cells resistant to EGFR inhibitors [19, 48]. It has been shown that EGFRvIII suppresses PDGFR $\beta$ expression in GBM and that EGFR inhibitors, by derepressing PDGFR $\beta$, render GBM dependent on PDGFR $\beta$ signaling for growth and survival [19]. Accordingly, silencing PDGFR $\beta$ significantly attenuated the growth of tumors from U87MG cells expressing kinase deadEGFRvIII subcutaneously implanted in mice [19]. Moreover, we found that U87MG/EGFRvIII cells resulted highly resistant to erlotinib and gefitinib and significantly inhibited in cell viability upon CL4 treatment only at high doses or by prolonging the incubation times. Despite the poor effect on cell viability, we found that incubating the cells with $200 \mathrm{nmol} / \mathrm{l} \mathrm{CL} 4$, as well as with $5 \mu \mathrm{mol} / 1$ gefitinib or erlotinib, causes a significant fold increase of PDGFR $\beta$. Altogether these observations prompt us to test aptamer-based combined treatments aimed at blocking both EGFRvIII and PDGFR $\beta$ signaling.

We have recently generated an aptamer, named Gint4.T, which binds to PDGFR $\beta$ and causes a strong inhibition of PDGF-BB ligand-dependent receptor activation in cell lines and primary cultures of GBM cells [22]. In addition, we have shown that, by targeting EGFRwt and PDGFR $\beta$, CL4 and Gint4.T synergize at slowing the growth of xenografts from U87MG cells [22]. Here, we demonstrated that the combined treatment of U87MG/EGFRvIII cells with CL4 and Gint4.T aptamers led to a consistent higher inhibition of cell growth with respect to each aptamer alone, without induction of cell death. Further, the anti-PDGFR $\beta$ aptamer also restored the cell sensibility to gefitinib treatment, thus confirming a greater advantage of targeting both EGFR/EGFRvIII and PDGFR $\beta$ over single receptor inhibition.

The expression of EGFRvIII is usually associated with EGFRwt amplification in GBM clinical samples, thus highlighting the potential benefit of the CL4 aptamer targeting both the wild-type and the mutated receptor. However, the efficacy of CL4, used in combination with the anti-PDGFR $\beta$ aptamer, was also extended to a PDGFR $\beta$-positive GBM primary cell line lacking endogenous EGFRwt and engineered to express EGFRvIII (VS-GB/EGFRvIII), thus indicating the relevance of blocking both EGFRvIII and PDGFR $\beta$ also in the absence of the wild-type receptor.

Future studies in animal models will help to determine whether this is a viable strategy for GBM treatment.

Further, it has been shown that in GBM cells, EGFRvIII transactivates other RTKs, including the hepatocyte growth factor (HGF) receptor (MET) and cotargeting of these RTKs has a potent antitumor efficacy, thus suggesting a potential strategy for treating EGFRvIIIexpressing gliomas [49]. Our present findings showing the ability of CL4 aptamer to inhibit EGFRvIII and the value of aptamer-based inhibition of EGFR and PDGFR $\beta$, strongly encourage to further test whether the aptamer will reveal effective in interfering with EGFRvIII-dependent crosstalk with other RTKs, in addition to PDGFR $\beta$.

Due to the essential advantages of oligonucleotide aptamers such as their lack of immunogenicity, high stability, low-cost and rapid production with high batch fidelity [50-53], CL4 and Gint4.T may represent an attractive alternative over exiting anti-EGFR and antiPDGFR $\beta$ therapeutics and will help to expand current limited management options for the treatment of GBM. 


\section{MATERIALS AND METHODS}

\section{Cell lines and transfection}

Growth conditions for human GBM U87MG and mouse NIH3T3 (American Type Culture Collection, Manassas, VA) cell lines were previously reported [21, 22]. VS-GB Primary cell culture from GBM specimens was derived and grown as described previously [22]. VS-GB/EGFRvIII and NIH/EGFRvIII were obtained from VS-GB and NIH3T3 cells, respectively, stably transfected with EGFRvIII plasmid (kindly provided by K. Latha, Anderson Cancer Center) by Lipofectamine 2000 (Invitrogen, Carlsbad, CA), selected in $800 \mu \mathrm{g} / \mathrm{ml}$ Zeocin (Invitrogen) and maintained in DMEM-F12 with 10\% fetal bovine serum (FBS) (VS-GB/EGFRvIII) or DMEM with $10 \%$ bovine calf serum (NIH/EGFRvIII) in $95 \%$ air $/ 5 \%$ $\mathrm{CO} 2$ atmosphere at $37^{\circ} \mathrm{C}$. NIH/EGFRwt were obtained from NIH3T3 cells stably transfected with EGFRwt plasmid (Addgene, kindly provided by M. Meyerson [54]) by Lipofectamine 2000 (Invitrogen) and selected in $10 \mu \mathrm{g} / \mathrm{ml}$ Puromycin dihydrochloride (Sigma-Aldrich, St. Louis, MO). Human GBM U87MG/EGFRvIII, Gli36 and Gli36/EGFRvIII cells were previously described [55, 56]. Human NSCLC HCC827 (American Type Culture Collection) were grown in RPMI-1640 supplemented with $10 \% \mathrm{FBS}$.

\section{Aptamers and treatments}

2'F-Py RNA aptamers (CL4, Gint4.T, CL4Sc and 5' FAM-labeled CL4) were synthesized by TriLink Biotechnologies and purchased from Tebu-bio srl (Magenta, Milan, Italy).

CL4:5'GCCUUAGUAACGUGCUUUGAUGUCG AUUCGACAGGAGGC3'.

CL4Sc, used as a negative control:5'UUCGUACC GGGUAGGUUGGCUUGCACAUAGAACGUGUCA3'. Gint4.T:5'UGUCGUGGGGCAUCGAGUAAAUG CAAUUCGACA3'.

Before each treatment, the aptamers were subjected to a short denaturation-renaturation step $\left(85^{\circ} \mathrm{C}\right.$ for 5 minutes, on ice for 2 minutes, $37^{\circ} \mathrm{C}$ for 10 minutes). For cell incubation longer than 24 hours, the treatment was renewed each day and the RNA concentration was determined to ensure the continuous presence of at least $200 \mathrm{nmol} / \mathrm{l}$ concentration, taking into account the 6 hourshalf-life of the aptamer in $10 \%$ serum.

\section{Protein extraction and Immunoblot}

For protein extraction, cells were lysed in lysis buffer containing $50 \mathrm{mM}$ Hepes (pH 7.5), $150 \mathrm{mM} \mathrm{NaCl}$,
1\% glycerol, 1\% Triton X-100, $1.5 \mathrm{mM} \mathrm{MgCl}, 5 \mathrm{mM}$ EGTA, $1 \mathrm{mM} \mathrm{Na3VO4,} \mathrm{supplemented} \mathrm{with} \mathrm{protease}$ inhibitors (Roche Diagnostics, Indianapolis, IN). Protein concentration was determined by the Bradford assay using Bovine serum albumin (BSA) (Panreac AppliChem, Darmstadt, Germany) as the standard. SDS-PAGE analysis, under reducing and non-reducing conditions, was carried out according to Laemmli in the presence and absence of 2-mercaptoethanol (Sigma-Aldrich), respectively. Gels were electroblotted into polyvinylidene difluoride membranes (Millipore Co., Bedford, MA) and filters were probed with the indicated primary antibodies: anti-phospho-EGFR (Tyr1068, indicated as pEGFR), anti-EGFR (intracellular), anti-phospho44/42 MAPK (D13.14.4E, indicated as pERK), anti-phospho-AKT (Ser473, indicated as pAKT), anti-AKT, anti-phosphoSTAT3 (indicated as pSTAT3), anti-STAT3, anti-PDGFR $\beta$ (Cell Signaling Technology Inc., Danvers, MA); antiERK1 (C-16), anti- $\alpha$-tubulin (TU-02), anti-vinculin (N19) (Santa Cruz Biotechnology, Santa Cruz, CA); antiPTEN (Y184; Abcam, Cambridge, MA).

Densitometric analyses were performed on at least two different expositions to assure the linearity of each acquisition using ImageJ (v1.46r). Blots shown are representative of at least three independent experiments.

\section{Binding of CL4 aptamer to the cells}

\section{Binding assay by RT-qPCR}

Binding was performed as described previously [57]. Briefly, the day before the treatment, cells were seeded in $3.5-\mathrm{cm}$ plates $\left(2 \times 10^{5}\right.$ cells $/$ plate $)$. Cells were incubated with $200 \mathrm{nmol} / 1$ and $400 \mathrm{nmol} / \mathrm{l} \mathrm{CL} 4$ or CL4Sc negative control, for 15 minutes at $37^{\circ} \mathrm{C}$ in the presence of $100 \mu \mathrm{g} / \mathrm{ml}$ polyinosine (Sigma-Aldrich) as a nonspecific competitor. Unbound RNA was removed by washing ( 3 x $500 \mu 1$ of ice-cold Dulbecco's PhosphateBuffered Saline (DPBS) and bound RNA was recovered by TRIzol (Invitrogen) containing $0.5 \mathrm{pmoles} / \mathrm{ml}$ of starting RNA library [55], used as a reference control and here indicated as random pool. Recovered RNA was reverse transcribed (RT) using M-MuLV Reverse Transcriptase (Roche Diagnostics) and specific 3' primers. The primers for the RT step were: CL4 3' primer, 5'-GCCTCCTGTCGAATCGA-3'; CL4Sc 3' primer, 5'-TGACACGTTCTATGTGCA-3'; random pool 3' primer, 5'-GCCTGTTGTGAGCCTCCTGTCGAA-3'. The RT protocol was as follows: the recovered RNA and the primers were heated at $65^{\circ} \mathrm{C}$ for 5 minutes, annealed at $22^{\circ} \mathrm{C}$ for 5 minutes and extended at $42^{\circ} \mathrm{C}$ for 30 minutes followed by an extension at $48^{\circ} \mathrm{C}$ for 30 minutes and enzyme inactivation at $95^{\circ} \mathrm{C}$ for 5 minutes. The product from the RT reaction was PCR amplified with iQ SYBR Green Supermix (Bio-Rad, Hercules, CA) in the presence of CL4, CL4Sc or 
random pool $5^{\prime}$ and $3^{\prime}$ primers. The $3^{\prime}$ primers were as in the RT step and the 5' primers were: CL4 5' primer,5'TAATACGACTCACTATAGGGGCCTTAGTAACG-3'; CL4Sc 5' primer,5'TAATACGACTCACTATAGGGTTCGTACCGGGT-3'; random pool 5' primer,5'-TAATACGACTCACTATAGGG AGACAAGAATAAACGCTCAA-3'. The qPCR protocol was as follows: the RT product was heated at $95^{\circ} \mathrm{C}$ for 2 minutes, followed by 40 cycles of heating at $95^{\circ} \mathrm{C}$ for 30 seconds, annealing at $55^{\circ} \mathrm{C}$ for 30 seconds, and extending at $60^{\circ} \mathrm{C}$ for 30 seconds. A melt curve stage by heating at $60-95^{\circ} \mathrm{C}$ was performed.

Reactions were all done in $25 \mu \mathrm{L}$ volume in triplicate. Data were normalized to the random pool reference control and to the cell number, as determined by counting cells cultured in conjunction with each experiment.

\section{Binding assay by confocal microscopy}

$\mathrm{NIH} /$ ctr and NIH/EGFRvIII were seeded on coverslip in 24-well $\left(10^{5}\right.$ cells/well) in DMEM (PAA, E15-009) supplemented with 10\% FBS (PAA, A15-151), 2 $\mathrm{mM}$ L-glutamine and 100 units/ml penicillin-streptomycin at $37^{\circ} \mathrm{C}$ in an atmosphere of $5 \% \mathrm{CO} 2 /$ air. After 24 hours cells were treated with $2.5 \mu \mathrm{mol} / 1$ FAM-labelled CL4 in DMEM without FBS for the indicated time. Then, cells were washed three times in DPBS and fixed in DPBS/PFA $4 \%$ for 20 minutes. For binding assay, unpermeabilized cells were subjected to blocking in DPBS/BSA $0.5 \%$ for 1 hour, and incubated with anti-EGFR antibody (AF231, R\&D system, Minneapolis, MN). After three washes in DPBS, cells were incubated with anti-goat Alexa Fluor 647 conjugated antibody (A21447, Life Technologies Italia, Monza, Italy). Finally, after three further washes in DPBS, cells were incubated with $1.5 \mu \mathrm{M} 4$ ',6-Diamidino2-phenylindole (DAPI, D9542, Sigma-Aldrich) and mounted with Fluorescence mounting medium (S3023, Dako Italia, Milan, Italy).

For endosome internalization assay, fixed cells were permeabilized with DPBS/Triton X-100 0.2\% for 5 minutes and then subjected to blocking in DPBS/BSA $0.5 \%$ for 1 hour. Cells were incubated with anti-EGFR antibody and anti-EEA1 (ab2900, Abcam), washed three times in DPBS, and incubated with anti-goat Alexa Fluor 647 conjugated and anti-rabbit Alexa Fluor 555 (A31572, Life Technologies Italia). Finally, after three further washes in DPBS, cells were incubated with $1.5 \mu \mathrm{M}$ DAPI and mounted with Fluorescence mounting medium.

Samples were visualized on a TSC SP5 confocal microscope (Leica) installed on an inverted LEICA DMI 6000CS microscope and equipped with an oil immersion PlanApo 63X 1.4 NA objective. Images were acquired using the LAS AF acquisition software (Leica).

\section{Binding assay by flow cytometry}

U87MG or U87MG/EGFRvIII cells were trypsinized and washed twice with $500 \mu \mathrm{l}$ DPBS. Cells $\left(2 \times 10^{5}\right)$ were incubated in the absence or in the presence of $2 \mu \mathrm{mol} / 1$ FAM-labelled CL4 in $100 \mu \mathrm{l}$ DPBS at $37^{\circ} \mathrm{C}$ for 30 minutes. Cells were washed twice with $500 \mu \mathrm{l}$ DPBS, suspended in $400 \mu \mathrm{l}$ DPBS and analyzed by flow cytometry. The fluorescence was determined with a Flow Cytometer (BD Accuri ${ }^{\mathrm{TM}}$ C6) by counting 20.000 events.

\section{UV induced cross-linking experiments and MALDI-TOF mass spectrometry}

Cross-linking experiments were carried out by irradiating samples with a UV lamp (Spectronics Corporation) at $254 \mathrm{~nm}$. In a typical experiment, an aliquot of the EGFR ectodomain protein (R\&D Systems) was combined with the CL4 aptamer in a 1:1 molar ratio in $50 \mathrm{mM}$ Tris- $\mathrm{HCl}$ buffer, $\mathrm{pH} 7.5$. The sample was then irradiated at $254 \mathrm{~nm}$ for 20 minutes at $25^{\circ} \mathrm{C}$ at a distance of $7 \mathrm{~cm}$. The cross-linked product was then digested with trypsin [enzyme/substrate ratio, 1:100 (w/w)] for 6 hours at $25^{\circ} \mathrm{C}$ in the same buffer, and enzymatic hydrolysis was carried out with $\mathrm{T} 1$ ribonuclease $\left(300\right.$ units at $37^{\circ} \mathrm{C}$ for 30 minutes). The resulting peptide mixture was then directly analyzed by MALDI-MS.

Positive Reflectron MALDI spectra were recorded on a Voyager DE STR instrument (Applied Biosystems, Framingham, MA). The MALDI matrix was prepared by dissolving $\alpha$-cyano-hydroxycinnamic powder in $70 \%$ acetonitrile and $30 \%$ citric acid $50 \mathrm{mM}$. Typically $1 \mu \mathrm{l}$ of matrix was applied to the metallic sample plate and $1 \mu \mathrm{l}$ of analyte was then added. The mixture thus obtained was then dried at room temperature. Acceleration and reflector voltages were set up as follows: target voltage at $20 \mathrm{kV}$, first grid at $65 \%$ of target voltage, delayed extraction at $400 \mathrm{~ns}$ to obtain the best signal-to-noise ratios and the best possible isotopic resolution. Mass calibration was performed using external peptide standards purchased from Applied Biosystems. Each spectrum represents the sum of 3,000 laser pulses from randomly chosen spots per sample position. Raw data were analyzed using the computer software provided by the manufacturers and are reported as monoisotopic masses.

\section{Cell migration and invasion}

For wound healing assay, U87MG/EGFRvIII and Gli36/EGFRvIII cells were plated in six-well plates and grown to subconfluence. The assay was performed as previously described [22], in the absence or in the presence of $200 \mathrm{nmol} / \mathrm{l} \mathrm{CL} 4$ or CL4Sc. The distance between the two edges of the scratch was measured by Image J (v1.46r) in three areas (top, middle and bottom), the average distance was quantified and the extent of wound closure was determined as follows: wound closure $(\%)=1-($ wound width $\mathrm{tx} /$ wound width t0) x 100. Each experiment was triplicated and performed three times 
independently.

For transwell migration assay, U87MG/EGFRvIII and Gli36/EGFRvIII cells were serum-starved overnight, in the presence of $200 \mathrm{nmol} / 1 \mathrm{CL} 4$ or CL4Sc, and then trypsinized, re-suspended in DMEM serum free, and counted. Cells $\left(5 \times 10^{4}\right.$ in $100 \mu 1$ serum-free medium per well) were seeded into the upper chamber of a 24well transwell (Transwell filters $8 \mu \mathrm{m}$ pore size; Corning Incorporate, Corning, NY) in the presence of $200 \mathrm{nmol} / 1$ CL4 or CL4Sc. The lower chamber was filled with $600 \mu \mathrm{l}$ of medium containing $5 \% \mathrm{FBS}$, as inducer of migration.

For invasion assays transwell filters were coated with Matrigel (BD Biosciences, NJ) diluted 1:4 in serumfree medium and left 45 minutes in incubator at $37^{\circ} \mathrm{C}$. Then the assay was performed as the migratory assay except that an higher number of cells $\left(1 \times 10^{5}\right)$ were exposed to $10 \%$ FBS.

After incubation at $37^{\circ} \mathrm{C}$ in humidified $5 \% \mathrm{CO}_{2}$ for indicated times, cells were visualized by staining with $0.1 \%$ crystal violet in $25 \%$ methanol and photographed. Stained cells were lysed in 1\% SDS and absorbance at 595 $\mathrm{nm}$ was measured in a microplate reader. Each experiment was triplicated and performed three times independently.

\section{Cell viability}

Cell viability was assessed with CellTiter 96 AQueous One Solution Cell Proliferation Assay (Promega BioSciences Inc., San Luis Obispo, CA) according to the manufacturer's instructions. In each assay, cells were plated in 96-well plates $\left(3.6 \times 10^{3}\right.$ cells/well). To assess cell viability in the presence of EGFR-TKIs, erlotinib (Cell Signaling) and gefitinib (LC Laboratories, Woburn, MA) were used, as indicated.

\section{Real-Time PCR}

RNA was extracted by TRizol (Invitrogen) according to the manufacturer's instructions. $1 \mu \mathrm{g}$ total RNA was reverse transcribed with iScript cDNA Synthesis Kit (Bio-Rad) and the resulting cDNA fragments were amplified by using iQ SYBR Green supermix (Bio-Rad). Primers used were: PDGFR $\beta$, Fwd 5'-AGGACACGCAGGAGGTCAT-3', Rev 5'-TTCTGCCAAAGCATGATGAG-3'; EGFRwt, Fwd 5'-TCCTTGGGAATTTGGAAATT-3', Rev 5'-GGCATAGGAATTTTCGTAGTACAT-3'; $\beta$-actin, Fwd 5'-CAAGAGATGGCCACGGCTGCT-3', Rev 5'-TCCTTCTGCATCCTGTCGGCA-3'. Relative mRNA quantization was performed by using the $\Delta \Delta \mathrm{Ct}$ method applying the equation $2^{-\Delta \Delta C t}$.

\section{Statistics}

Statistical values were defined using GraphPad Prism version 6.00 for Windows by $t$-test. $P$ value $<0.05$ was considered significant.

\section{ACKNOWLEDGMENTS}

We are grateful to Khatri Latha and Matthew Meyerson for providing EGFRvIII and EGFRwt plasmid, respectively.

\section{FUNDINGS}

This work was supported by grants from Consiglio Nazionale delle Ricerche (CNR), Association for International Cancer Research (AICR) No 11-0075 (L.C.), Associazione Italiana per la Ricerca sul Cancro (AIRC) IG 11781 (L.C.) and Istituto Toscano Tumori, Regione Toscana. S.C. was supported by a Fondazione Umberto Veronesi Fellowship.

\section{CONFLICTS OF INTEREST}

The authors declare no conflict of interest.

\section{REFERENCES}

1. Stupp R, Hegi ME, Mason WP, van den Bent MJ, Taphoorn MJ, Janzer RC, Ludwin SK, Allgeier A, Fisher B, Belanger K, Hau P, Brandes AA, Gijtenbeek J, et al. Effects of radiotherapy with concomitant and adjuvant temozolomide versus radiotherapy alone on survival in glioblastoma in a randomised phase III study: 5-year analysis of the EORTCNCIC trial. Lancet Oncol. 2009; 10: 459-466.

2. Bonavia R, Inda MM, Cavenee WK, Furnari FB. Heterogeneity maintenance in glioblastoma: a social network. Cancer Res. 2011; 71: 4055-4060.

3. Brennan CW, Verhaak RG, McKenna A, Campos B, Noushmehr H, Salama SR, Zheng S, Chakravarty D, Sanborn JZ, Berman SH, Beroukhim R, Bernard B, Wu CJ, et al. The somatic genomic landscape of glioblastoma. Cell. 2013; 155: 462-477.

4. Shinojima N, Tada K, Shiraishi S, Kamiryo T, Kochi M, Nakamura H, Makino K, Saya H, Hirano H, Kuratsu J, Oka K, Ishimaru Y, Ushio Y. Prognostic value of epidermal growth factor receptor in patients with glioblastoma multiforme. Cancer Res. 2003; 63: 6962-6970.

5. Heimberger AB, Suki D, Yang D, Shi W, Aldape K. The natural history of EGFR and EGFRvIII in glioblastoma patients. J Transl Med. 2005; 3: 38.

6. Jeuken J, Sijben A, Alenda C, Rijntjes J, Dekkers M, BootsSprenger S, McLendon R, Wesseling P. Robust detection of EGFR copy number changes and EGFR variant III: 
technical aspects and relevance for glioma diagnostics. Brain Pathol. 2009; 19: 661-671.

7. Dunn GP, Rinne ML, Wykosky J, Genovese G, Quayle SN, Dunn IF, Agarwalla PK, Chheda MG, Campos B, Wang A, Brennan C, Ligon KL, Furnari F, et al. Emerging insights into the molecular and cellular basis of glioblastoma. Genes Dev. 2012; 26: 756-784.

8. Nishikawa R, Ji XD, Harmon RC, Lazar CS, Gill GN, Cavenee WK, Huang HJ. A mutant epidermal growth factor receptor common in human glioma confers enhanced tumorigenicity. Proc Natl Acad Sci U S A. 1994; 91: 77277731.

9. Nagane M, Coufal F, Lin H, Bögler O, Cavenee WK, Huang HJ. A common mutant epidermal growth factor receptor confers enhanced tumorigenicity on human glioblastoma cells by increasing proliferation and reducing apoptosis. Cancer Res. 1996; 56: 5079-5086.

10. Feng H, Hu B, Jarzynka MJ, Li Y, Keezer S, Johns TG, Tang CK, Hamilton RL, Vuori K, Nishikawa R, Sarkaria JN, Fenton T, Cheng T, et al. Phosphorylation of dedicator of cytokinesis 1 (Dock180) at tyrosine residue Y722 by Src family kinases mediates EGFRvIII-driven glioblastoma tumorigenesis. Proc Natl Acad Sci U S A. 2012; 109: 30183023.

11. Feng H, Hu B, Vuori K, Sarkaria JN, Furnari FB, Cavenee WK, Cheng SY. EGFRvIII stimulates glioma growth and invasion through PKA-dependent serine phosphorylation of Dock180. Oncogene. 2014; 33: 2504-2512.

12. Inda MM, Bonavia R, Mukasa A, Narita Y, Sah DW, Vandenberg S, Brennan C, Johns TG, Bachoo R, Hadwiger P, Tan P, Depinho RA, Cavenee W, Furnari F. Tumor heterogeneity is an active process maintained by a mutant EGFR-induced cytokine circuit in glioblastoma. Genes Dev. 2010; 24: 1731-1745.

13. Luwor RB, Zhu HJ, Walker F, Vitali AA, Perera RM, Burgess AW, Scott AM, Johns TG. The tumor-specific de27 epidermal growth factor receptor (EGFR) promotes cells survival and heterodimerizes with the wild-type EGFR. Oncogene. 2004; 23: 6095-6104.

14. Li L, Chakraborty S, Yang CR, Hatanpaa KJ, Cipher DJ, Puliyappadamba VT, Rehman A, Jiwani AJ, Mickey B, Madden C, Raisanen J, Burma S, Saha D, et al. An EGFR wild type-EGFRvIII-HB-EGF feed-forward loop regulates the activation of EGFRvIII. Oncogene. 2014; 33: 4253 4264.

15. Fan QW, Cheng CK, Gustafson WC, Charron E, Zipper P, Wong RA, Chen J, Lau J, Knobbe-Thomsen C, Weller M, Jura N, Reifenberger G, Shokat KM, Weiss WA. EGFR phosphorylates tumor-derived EGFRvIII driving STAT3/5 and progression in glioblastoma. Cancer Cell. 2013; 24: 438-449.

16. Cloughesy TF, Cavenee WK, Mischel PS. Glioblastoma: from molecular pathology to targeted treatment. Annu Rev Pathol. 2014; 9: 1-25.
17. Gan HK, Cvrljevic AN, Johns TG. The epidermal growth factor receptor variant III (EGFRvIII): where wild things are altered. FEBS J. 2013; 280: 5350-5370.

18. Bastien JI, McNeill KA, Fine HA. Molecular characterizations of glioblastoma, targeted therapy, and clinical results to date. Cancer. 2015; 121: 502-516.

19. Akhavan D, Pourzia AL, Nourian AA, Williams KJ, Nathanson D, Babic I, Villa GR, Tanaka K, Nael A, Yang H, Dang J, Vinters HV, Yong WH, et al. De-repression of PDGFR $\beta$ transcription promotes acquired resistance to EGFR tyrosine kinase inhibitors in glioblastoma patients. Cancer Discov. 2013; 3: 534-547.

20. Bax DA, Gaspar N, Little SE, Marshall L, Perryman L, Regairaz M, Viana-Pereira M, Vuononvirta R, Sharp SY, Reis-Filho JS, Stávale JN, Al-Sarraj S, Reis RM, et al. EGFRvIII deletion mutations in pediatric high-grade glioma and response to targeted therapy in pediatric glioma cell lines. Clin Cancer Res. 2009; 15: 5753-5761.

21. Esposito CL, Passaro D, Longobardo I, Condorelli G, Marotta P, Affuso A, de Franciscis V, Cerchia L. A neutralizing RNA aptamer against EGFR causes selective apoptotic cell death. PLoS One. 2011; 6: e24071.

22. Camorani S, Esposito CL, Rienzo A, Catuogno S, Iaboni M, Condorelli G, de Franciscis V, Cerchia L. Inhibition of receptor signaling and of glioblastoma-derived tumor growth by a novel PDGFR $\beta$ aptamer. Mol Ther. 2014; 22: 828-841.

23. Bishayee A, Beguinot L, Bishayee S. Phosphorylation of tyrosine 992, 1068, and 1086 is required for conformational change of the human epidermal growth factor receptor c-terminal tail. Mol Biol Cell. 1999; 10: 525-536.

24. Goldenring JR. Recycling endosomes. Curr Opin Cell Biol. 2015; 35: 117-122.

25. Pines G, Huang PH, Zwang Y, White FM, Yarden Y. EGFRvIV: a previously uncharacterized oncogenic mutant reveals a kinase autoinhibitory mechanism. Oncogene. 2010; 29: 5850-5860.

26. Kancha RK, von Bubnoff N, Duyster J. Asymmetric kinase dimer formation is crucial for the activation of oncogenic EGFRvIII but not for ERBB3 phosphorylation. Cell Commun Signal. 2013; 11: 39.

27. Greenall SA, Donoghue JF, Gottardo NG, Johns TG, Adams TE. Glioma-specific Domain IV EGFR cysteine mutations promote ligand-induced covalent receptor dimerization and display enhanced sensitivity to dacomitinib in vivo. Oncogene. 2015; 34: 1658-1666.

28. Ymer SI, Greenall SA, Cvrljevic A, Cao DX, Donoghue JF, Epa VC, Scott AM, Adams TE, Johns TG. Glioma Specific Extracellular Missense Mutations in the First Cysteine Rich Region of Epidermal Growth Factor Receptor (EGFR) Initiate Ligand Independent Activation. Cancers (Basel). 2011; 3: 2032-2049.

29. Hwang Y, Chumbalkar V, Latha K, Bogler O. Forced dimerization increases the activity of $\triangle$ EGFR/EGFRvIII 
and enhances its oncogenicity. Mol Cancer Res. 2011; 9: 1199-1208.

30. Furnari FB, Lin H, Huang HS, Cavenee WK. Growth suppression of glioma cells by PTEN requires a functional phosphatase catalytic domain. Proc Natl Acad Sci U S A. 1997; 94: 12479-12484.

31. Zhu Y, Shah K. Multiple lesions in receptor tyrosine kinase pathway determine glioblastoma response to pan-ERBB inhibitor PF-00299804 and PI3K/mTOR dual inhibitor PF05212384. Cancer Biol Ther. 2014; 15: 815-822.

32. Maier D, Jones G, Li X, Schönthal AH, Gratzl O, Van Meir EG, Merlo A. The PTEN lipid phosphatase domain is not required to inhibit invasion of glioma cells. Cancer Res. 1999; 59: 5479-5482.

33. Zheng Q, Han L, Dong Y, Tian J, Huang W, Liu Z, Jia X, Jiang T, Zhang J, Li X, Kang C, Ren H. JAK2/STAT3 targeted therapy suppresses tumor invasion via disruption of the EGFRvIII/JAK2/STAT3 axis and associated focal adhesion in EGFRvIII-expressing glioblastoma. Neuro Oncol. 2014; 16: 1229-1243.

34. Cai XM, Tao BB, Wang LY, Liang YL, Jin JW, Yang Y, $\mathrm{Hu}$ YL, Zha XL. Protein phosphatase activity of PTEN inhibited the invasion of glioma cells with epidermal growth factor receptor mutation type III expression. Int J Cancer. 2005; 117: 905-912.

35. Li L, Dutra A, Pak E, Labrie JE 3rd, Gerstein RM, Pandolfi PP, Recht LD, Ross AH. EGFRvIII expression and PTEN loss synergistically induce chromosomal instability and glial tumors. Neuro Oncol. 2009; 11: 9-21.

36. Sasaki H, Zlatescu MC, Betensky RA, Ino Y, Cairncross JG, Louis DN. PTEN is a target of chromosome 10q loss in anaplastic oligodendrogliomas and PTEN alterations are associated with poor prognosis. Am J Pathol. 2001; 159: 359-367.

37. Albini A. Tumor and endothelial cell invasion of basement membranes. The matrigel chemoinvasion assay as a tool for dissecting molecular mechanisms. Pathol Oncol Res. 1998; 4: $230-241$.

38. Engelman JA, Mukohara T, Zejnullahu K, Lifshits E, Borrás AM, Gale CM, Naumov GN, Yeap BY, Jarrell E, Sun J, Tracy S, Zhao X, Heymach JV, et al. Allelic dilution obscures detection of a biologically significant resistance mutation in EGFR-amplified lung cancer. J Clin Invest. 2006; 116: 2695-2706.

39. Gan HK, Kaye AH, Luwor RB. The EGFRvIII variant in glioblastoma multiforme. J Clin Neurosci. 2009 ; 16: 748754.

40. Hatanpaa KJ, Burma S, Zhao D, Habib AA. Epidermal growth factor receptor in glioma: signal transduction, neuropathology, imaging, and radioresistance. Neoplasia. 2010; 12 : 675-684.

41. Pedersen MW, Pedersen N, Ottesen LH, Poulsen HS. Differential response to gefitinib of cells expressing normal EGFR and the mutant EGFRvIII. Br J Cancer. 2005; 93:
915-923.

42. Montgomery RB. Antagonistic and agonistic effects of quinazoline tyrosine kinase inhibitors on mutant EGF receptor function. Int J Cancer. 2002; 101: 111-117.

43. Groner B, Lucks P, Borghouts C. The function of Stat 3 in tumor cells and their microenvironment. Semin Cell Dev Biol. 2008; 19: 341-350.

44. Iwamaru A, Szymanski S, Iwado E, Aoki H, Yokoyama T, Fokt I, Hess K, Conrad C, Madden T, Sawaya R, Kondo S, Priebe W, Kondo Y. A novel inhibitor of the STAT3 pathway induces apoptosis in malignant glioma cells both in vitro and in vivo. Oncogene. 2007; 26: 2435-2444.

45. Johns TG, Perera RM, Vernes SC, Vitali AA, Cao DX, Cavenee WK, Scott AM, Furnari FB. The efficacy of epidermal growth factor receptor-specific antibodies against glioma xenografts is influenced by receptor levels, activation status, and heterodimerization. Clin Cancer Res. 2007; 13: 1911-1925.

46. Xing WJ, Zou Y, Han QL, Dong YC, Deng ZL, Lv XH, Jiang T, Ren H. Effects of epidermal growth factor receptor and phosphatase and tensin homologue gene expression on the inhibition of U87MG glioblastoma cell proliferation induced by protein kinase inhibitors. Clin Exp Pharmacol Physiol. 2013; 40: 13-21.

47. Lal A, Glazer CA, Martinson HM, Friedman HS, Archer GE, Sampson JH, Riggins GJ. Mutant epidermal growth factor receptor up-regulates molecular effectors of tumor invasion. Cancer Res. 2002; 62: 3335-3339.

48. Hu J, Muller KA, Furnari FB, Cavenee WK, VandenBerg SR, Gonias SL. Neutralizing the EGF receptor in glioblastoma cells stimulates cell migration by activating uPAR-initiated cell signaling. Oncogene. 2015; 34: 40784088.

49. Greenall SA, Donoghue JF, Van Sinderen M, Dubljevic V, Budiman S, Devlin M, Street I, Adams TE, Johns TG. EGFRvIII-mediated transactivation of receptor tyrosine kinases in glioma: mechanism and therapeutic implications. Oncogene. 2015; 1-11.

50. Keefe AD, Pai S, Ellington A. Aptamers as therapeutics. Nat Rev Drug Discov. 2010; 9: 537-550.

51. Cerchia L, de Franciscis V. Targeting cancer cells with nucleic acid aptamers. Trends Biotechnol. 2010; 28: 517525.

52. Camorani S, Cerchia L. Oligonucleotide aptamers for glioma targeting: an update. Cent Nerv Syst Agents Med Chem. 2015; 15: 126-137.

53. Thiel KW, Giangrande PH. Therapeutic applications of DNA and RNA aptamers. Oligonucleotides. 2009; 19: 209222.

54. Greulich H, Chen TH, Feng W, Jänne PA, Alvarez JV, Zappaterra M, Bulmer SE, Frank DA, Hahn WC, Sellers WR, Meyerson M. Oncogenic transformation by inhibitorsensitive and -resistant EGFR mutants. PLoS Med. 2005; 2: e313. 
55. Cerchia L, Esposito CL, Jacobs AH, Tavitian B, de Franciscis V. Differential SELEX in human glioma cell lines. PLoS One. 2009; 4: e7971.

56. Rueger MA, Winkeler A, Miletic H, Kaestle C, Richter R, Schneider G, Hilker R, Heneka MT, Ernestus RI, Hampl JA, Fraefel C, Jacobs AH. Variability in infectivity of primary cell cultures of human brain tumors with HSV-1 amplicon vectors. Gene Ther. 2005; 12: 588-96.

57. Thiel WH, Bair T, Peek AS, Liu X, Dassie J, Stockdale KR, Behlke MA, Miller FJ Jr, Giangrande PH. Rapid identification of cell-specific, internalizing RNA aptamers with bioinformatics analyses of a cell-based aptamer selection. PLoS One. 2012; 7: e43836. 